\title{
Synaptic Vesicles, Mitochondria, and Actin Alterations in SMN-deficient Mice
}

Margret Neher

Göttingen 

Der Medizinischen Fakultät der Georg-August-Universität

Göttingen

eingereicht von Prof. Dr. J.H. Weishaupt

\title{
Synaptic Vesicles, Mitochondria, and Actin Alterations in SMN-deficient Mice
}

\author{
INAUGURAL - DisSERTATION \\ zur Erlangung des Doktorgrades \\ der Medizinischen Fakultät \\ der Georg-August-Universität zu Göttingen
}

vorgelegt von

Margret Neher

aus Göttingen

Göttingen 2014 
Der experimentelle Teil dieser Arbeit entstand in der Abteilung Fisiología Médica y Biofisica an der Medizinischen Fakultät der Universität Sevilla im Zeitraum von Februar 2010 bis Oktober 2010 unter der Leitung von Prof. Dr. L. Tabares.

Dekan: Prof. Dr. rer. nat. H.K. Kroemer

I. Bericherstatter: Prof. Dr. J.H. Weishaupt

II. Berichterstatter: Prof. S. Rizzoli

III. Berichterstatterin: Prof. M. Schön

Tag der mündlichen Prüfung: 27.05.2015 


\section{Contents}

1 Introduction 1

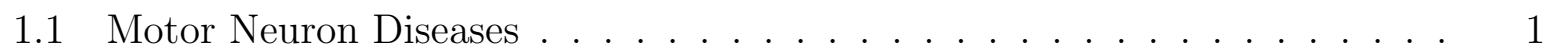

$1.2 \quad$ Spinal Muscular Atrophy (SMA) $\ldots \ldots \ldots \ldots \ldots$

1.3 The Genetic Principles of Proximal SMA $\ldots \ldots \ldots . \ldots . \ldots . \ldots$

1.4 The FL-SMN Protein $\ldots \ldots \ldots \ldots \ldots$. . . . . . . . . . . . . . . . . . 4

1.4.1 Assembly and Distribution of the FL-SMN Protein . . . . . . . . 4

1.4 .2 The SMN-Complex $\ldots \ldots \ldots \ldots \ldots \ldots$

\begin{tabular}{lll}
\hline 1.4 .3 & The Role of SMN in SnRNP Biogenesis and pre-mRNA Splicing . . $\quad 7$
\end{tabular}

1.4 .4 Motor Neuron Specific Function of SMN . . . . . . . . . . . . . . 9

1.5 Mouse Models of SMA $\ldots \ldots \ldots \ldots \ldots$

1.6 Neuro Muscular Junction (NMJ) Pathology in SMA . . . . . . . . . . . . . 11

1.6 .1 Synaptic Vesicles $\ldots \ldots \ldots \ldots \ldots \ldots$

1.6 .2 Mitochondria $\ldots \ldots \ldots \ldots \ldots \ldots \ldots$

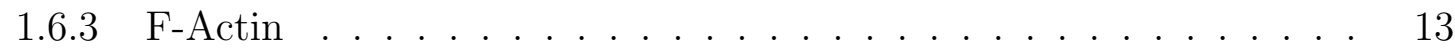

1.6 .4 The Questions and Objectives of this Study . . . . . . . . . . 15

$\begin{array}{llr}2 & \text { Materials and Methods } & 17\end{array}$

2.1 Materials . . . . . . . . . . . . . . . . . . . . . . . . . 17

2.1 .1 Mouse Model . . . . . . . . . . . . . . . . . . . . . . . . . 17

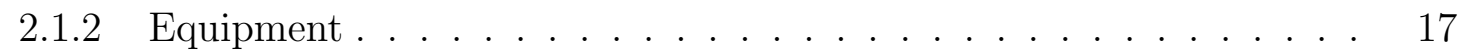

$2.1 .3 \quad$ Genotyping $\ldots \ldots \ldots \ldots \ldots \ldots$

2.1 .4 Immunocytochemistry . . . . . . . . . . . . . . . . . . . . 18

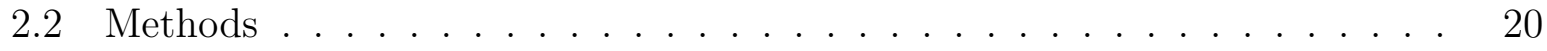

2.2 .1 Genotyping $\ldots \ldots \ldots \ldots \ldots \ldots$

2.2 .2 Muscle Dissection . . . . . . . . . . . . . . . . . . . . . . . 22

$2.2 .3 \quad$ Immunocytochemistry and Toxin-Conjugated Labeling . . . . . . . 23

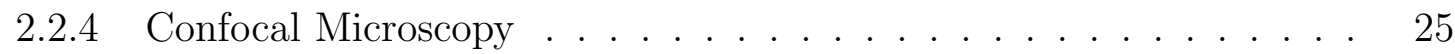

2.2 .5 Image Analysis with ImageJ $\ldots \ldots \ldots \ldots \ldots \ldots$

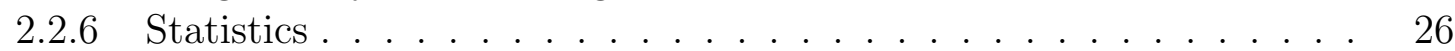

$\begin{array}{lll}3 & \text { Results } & 27\end{array}$

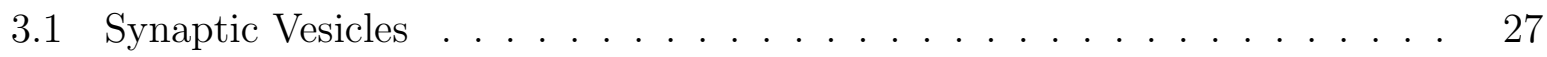

3.1 .1 Deficits in Synaptic Vesicle Maturation . . . . . . . . . . . . 27 
3.1 .2 VAChT and SV2 colocalize in SMA Motor Terminals . . . . . . . . 31

3.1.3 A reduced SV pool can coexist with a mature Postsynaptic Terminal in LAL Muscle. . . . . . . . . . . . . . . . . . . . . . . . . . . . . 32

3.2 Mitochondria . . . . . . . . . . . . . . . . . . . 34

3.2 .1 Mitochondria Clusters are smaller in SMA Motor Terminals . . . . 34

3.2 .2 Co-clustering of Mitochondria and SV clusters . . . . . . . . . . . . 35

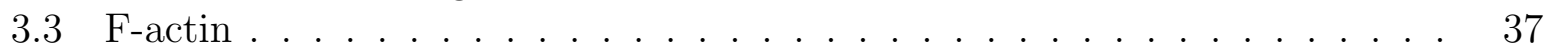

$3.3 .1 \quad$ F-actin forms ring-like Structures around SV Clusters . . . . . . . . 37

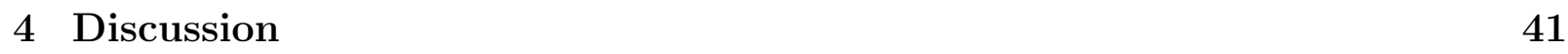

$4.1 \quad$ Synaptic Vesicle Clusters remain small in SMA mice during Maturation . . 41

4.2 Selective Vulnerability of Motor Neurons . . . . . . . . . . . . . . . . 43

4.3 Mitochondrial Clusters are smaller in SMA Motor Terminals . . . . . . . . 44

4.4 SV Clusters and Mitochondria are localized in Pairs . . . . . . . . . . . . . 46

4.5 Actin Dynamics in SMA Pathogenesis . . . . . . . . . . . . . . . . 46

$\begin{array}{llr}5 \text { Abstract } & 49\end{array}$

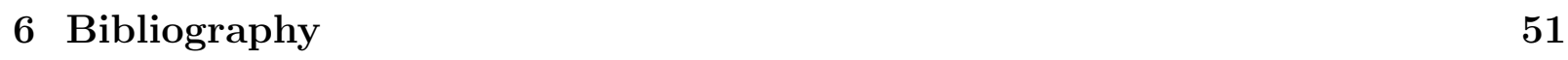

\begin{tabular}{lr}
\hline List of abbreviations & 60
\end{tabular} 


\section{Chapter 1}

\section{Introduction}

\section{$1.1 \quad$ Motor Neuron Diseases}

This heterogeneous group of diseases is characterized by a predominant affection of the motor neuron system. The chronic progression of these diseases can still hardly be influenced by therapeutic intervention. The degeneration can affect the first motor neuron (central paralysis), the second motor neuron (peripheral paralysis), or both systems in combination (Poeck and Hacke 2001). An affection of the first motor neuron is characterized by an increase of the muscle tone and enhanced muscle reflexes, while an affection of the second motor neuron is characterized by atonic paralysis and extinction of muscle reflexes (Trepel 2003). Spastic spinal paralysis is an example for a degeneration of the first motor neuron, while spinal muscular atrophy (SMA) belongs to motor neuron diseases with degeneration of the second motor neuron. The prevalent amyotrophic lateral sclerosis (ALS) shows the nearly unique mixed pattern of a central and peripheral paralysis. One well-known ALS patient is the astrophysicist Stephen Hawking, who develops fascinating theories on the origin and evolution of galaxies, while being captured by his own body.

\subsection{Spinal Muscular Atrophy (SMA)}

There are different forms of SMA.The following study refers to the so-called proximal spinal muscular atrophy, characterized by degeneration of the second motor neurons and skeletal muscular atrophy. The disease is autosomal recessive and caused by a deletion of, or mutations in, a single gene, the survival motor neuron 1 (SMN1) gene. After cystic fibrosis, proximal SMA is the most common autosomal recessive disorder in humans, with a carrier frequency of approximately 1 in 35 and therefore an incidence of 1 in 6000. It is also the most common genetic cause of infant mortality (Monani 2005).

There are three types of proximal SMA ranging in severity from very severe (type I) to intermediate (type II) to mild (type III) (Pearn 1980). Moreover, there are numerous other less frequent forms of SMA with a different genetic background but similar phenotype (Table 1). The leading symptoms of proximal SMA are a progressive predominant proximal 


\begin{tabular}{|c|c|c|c|c|}
\hline SMA Type & $\begin{array}{l}\text { Mode of } \\
\text { Inheritance }\end{array}$ & $\begin{array}{l}\text { Gene Chromosome } \\
\text { Location }\end{array}$ & $\begin{array}{ll}\text { Phenotype } & \text { Disease } \\
\text { Symptoms } & \\
\end{array}$ & $\begin{array}{l}\text { Onset of the Dis- } \\
\text { ease }\end{array}$ \\
\hline $\begin{array}{l}\text { Proximal SMA's Type } \\
\text { I (Werdnig- Hoffmann) }\end{array}$ & $\begin{array}{l}\text { Autosomal } \\
\text { recessive }\end{array}$ & SMN1; 5q11.2-13.3 & $\begin{array}{l}\text { Proximal muscle weak- } \\
\text { ness, patients never sit } \\
\text { unaided; death }<2 \\
\text { years }\end{array}$ & $<6$ months \\
\hline $\begin{array}{l}\text { Type II (intermediate } \\
\text { chronic form) }\end{array}$ & $\begin{array}{l}\text { Autosomal } \\
\text { recessive }\end{array}$ & SMN1; 5q11.2-13.3 & $\begin{array}{l}\text { Proximal muscle } \\
\text { weakness, patients sit } \\
\text { unaided but become } \\
\text { wheelchair bound, } \\
\text { develop Scoliosis of } \\
\text { spine }\end{array}$ & $6-18$ months \\
\hline $\begin{array}{l}\text { Type III (Kugelberg- } \\
\text { Welander) }\end{array}$ & $\begin{array}{l}\text { Autosomal re- } \\
\text { cessive }\end{array}$ & SMN1; 5q11.2-13.3 & $\begin{array}{l}\text { Proximal muscle weak- } \\
\text { ness, patients walk un- } \\
\text { aided, normal lifespan }\end{array}$ & $>18$ months \\
\hline Distal SMA & $\begin{array}{l}\text { Autosomal re- } \\
\text { cessive }\end{array}$ & $11 q 13$ & $\begin{array}{l}\text { Distal muscle weak- } \\
\text { ness, diaphragmatic in- } \\
\text { volvement }\end{array}$ & 2 months -20 years \\
\hline $\begin{array}{l}\text { SMARD (Spinal Mus- } \\
\text { cular Atrophy Respira- } \\
\text { tory Distress) }\end{array}$ & $\begin{array}{ll}\text { Autosomal re- } \\
\text { cessive }\end{array}$ & IGHMBP2; 11q13.2 & $\begin{array}{lr}\text { Distal lower limb weak- } \\
\text { ness, diaphragmatic } \\
\text { weakness, } & \text { sensory, } \\
\text { autonomic } & \text { neurons } \\
\text { also affected } & \\
\end{array}$ & $1-6$ months \\
\hline X-linked infantile SMA & X-linked & Xp11.3-q11.2 & $\begin{array}{l}\text { Arthrogryposis, res- } \\
\text { piratory insufficiency, } \\
\text { scoliosis, chest defor- } \\
\text { mities, loss of anterior } \\
\text { horn cells at birth }\end{array}$ & at birth \\
\hline Distal SMA IV & $\begin{array}{l}\text { Autosomal } \\
\text { dominant }\end{array}$ & $7 \mathrm{p} 15$ & $\begin{array}{l}\text { Distal muscles affected, } \\
\text { bilateral weakness in } \\
\text { hands, atrophy of } \\
\text { thenar eminencmotor } \\
\text { neurone and peritoneal } \\
\text { muscle }\end{array}$ & $12-36$ years \\
\hline
\end{tabular}

Table 1: Modes of inheritance, gene location of the underlying mutation, phenotype and onset of the different forms of SMA. Note that the three types of proximal SMA have the same genetic defect but they differ in their phenotypes with lifespan ranging from under 2 years to normal. The other forms of SMA have miscellaneous modes of inheritance and genetic background (from Monani, 2005, p 886; reproduced with kind permission from Elsevier).

paresis, which appears always symmetric, and displays muscular fasciculation. The muscle reflexes are abolished. Vegetative functions, like bleb and gut evacuations, are not generally affected. Furthermore, no disturbance of the intelligence of patients is apparent. The various forms of SMA are very different in their time course and prognosis (Poeck and Hacke 2001).

SMA type I (Werdnig-Hoffmann) The acute type I form is characterized by severe, generalized muscle weakness and hypotonia at birth or within the next 3 months. The paralysis begins in the pelvic muscles and progresses from the extremities and from cranial towards the facial muscles. The muscular weakness of the inspiratory muscles leads to atelectasis, which promotes the development of infection and inflammatory processes. 
Death from respiratory failure or pneumonia occurs within the first two years (Poeck and Hacke 2001).

SMA type II (intermediate - chronic form) The onset of the disease is later than in type I, at an age between 6 and 18 months. The type II patients learn to sit and mostly to crawl while walking is impossible (Kunze, 1999). Although most patients become older than two years pulmonary complications are leading to an early death (Kunze, 1999).

SMA type III (Kugelberg-Welander) The mildest form of proximal SMA can be symptomless until the early adulthood. The onset is mostly within ages 2 and 17 years. A proximal weakness of the legs starts after an initially normal motor development. This might first be noticeable through difficulties in climbing stairs and standing up. In the later disease course most patients become dependent on a wheel chair. The life span is not considerably shortened.

\subsection{The Genetic Principles of Proximal SMA}

All three forms of proximal SMA are autosomal recessive. Regardless of the disease severity, 95\% of all patients carry a deletion in a gene containing nine exons that localizes to chromosome 5q11.2-13.3. This gene is termed the telomeric survival of motor neuron gene (SMN1). The remaining 5\% carry small mutations in the gene. In humans the SMN1 gene lies within a $500 \mathrm{~kb}$ inverted-duplicated region. Through the duplication of this region the centromeric half contains an almost identical copy gene, SMN2 (Lefebvre et al 1995). SMA patients lack the telomeric SMN1 gene, but they have at least one copy of SMN2. This, however, produces only around 10\% functional SMN protein and therefore can not compensate for the lack of the former. The difference in expression between the two genes is due to a translational silent single nucleotide ( $\mathrm{C}$ to $\mathrm{T}$ ) transition inside SMN2 exon 7. This critical transition leads to an alternative splicing of the SMN2 gene, resulting in a shortened gene product (SMN $\Delta$ Ex7) lacking exon 7 . This makes a genetic diagnosis of SMA relatively straightforward, based on a simple PCR reaction (Dreesen et al 1998). Due to the shorter length of the SMN2 transcript compared to the SMN1 transcript both genes can be distinguish from each other through gel electrophoresis. The SMN $\Delta 7$ isoform is unstable and rapidly degraded. While the SMN1- transcript is almost $100 \%$ translated to functional full-length protein (FL-SMN), only $10 \%$ of SMN2 transcript translated to FL-SMN protein. Patients with a deletion in the SMN1 gene, therefore, express insufficient levels of functional FL-SMN protein. Figure 1 shows the molecular basis of SMA: transcription and translation of SMN1 and SMN2-gene as well as the resulting amounts of protein (Monani 2005).

The number of SMN2 genes varies in the population from 1 to 6 copies. The greater the number of SMN2 genes, the more FL-SMN protein is produced and the milder is the disease phenotype (McAndrew et al 1997) (Feldkötter et al 2002). This explains the range in severity among SMA type-I, type-II, and type-III patients. A direct correlation between 


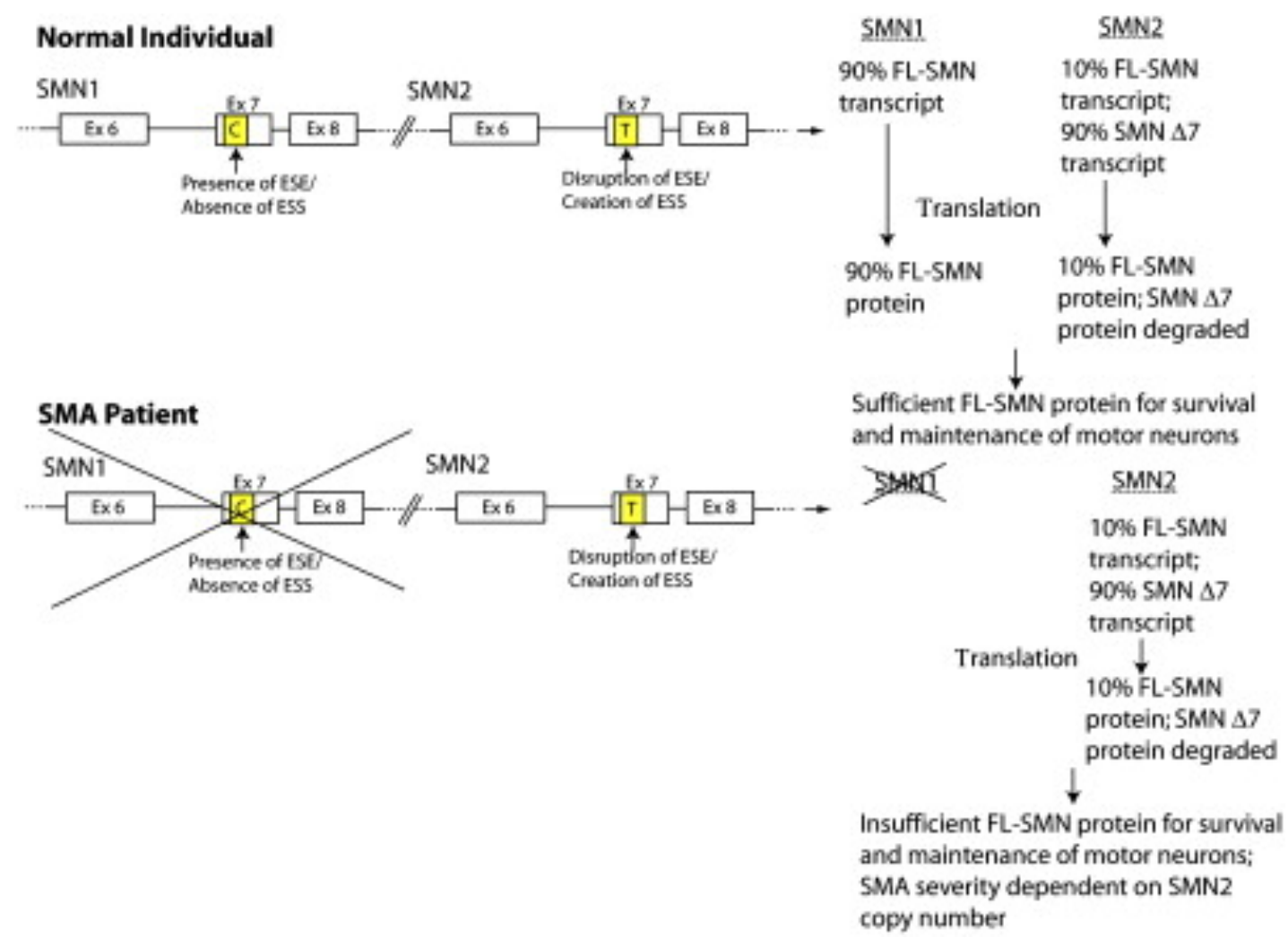

Figure 1: The molecular basis of the proximal spinal muscular atrophy depicting the two major genes involved in the disease, SMN1 and the modifier SMN2. Almost $100 \%$ of the SMN1 transcript is translated to functional full-length SMN protein while only $10 \%$ of the SMN2 transcript is translated to FL-SMN. In SMA patients homozygous deletion or mutation in the SMN1 gene leads to insufficient levels of SMN protein for survival and maintenance of motor neurons. The amount of FL-SMN protein levels in patients therefore determines the severity of the disease, depending on the number of SMN2 copies ( Monani et al. 2005, p 887; reproduced with kind permission from Elsevier).

the amounts of full length SMN-expression and severity of the phenotype demonstrates that SMA is due to a classical gene dose effect.

In essence, SMA results from low levels of the FL-SMN protein.

\subsection{The FL-SMN Protein}

\subsubsection{Assembly and Distribution of the FL-SMN Protein}

The FL-SMN protein contains 294 amino acids and has a molecular weight of 38 kilo Dalton $(\mathrm{kDa})$. It is ubiquitously expressed and does not exhibit homology to any previously identified protein. The necessity of the SMN for cellular survival and function has been proven in the following organisms and cell types: human, mouse, chicken, DT40 cells, - 


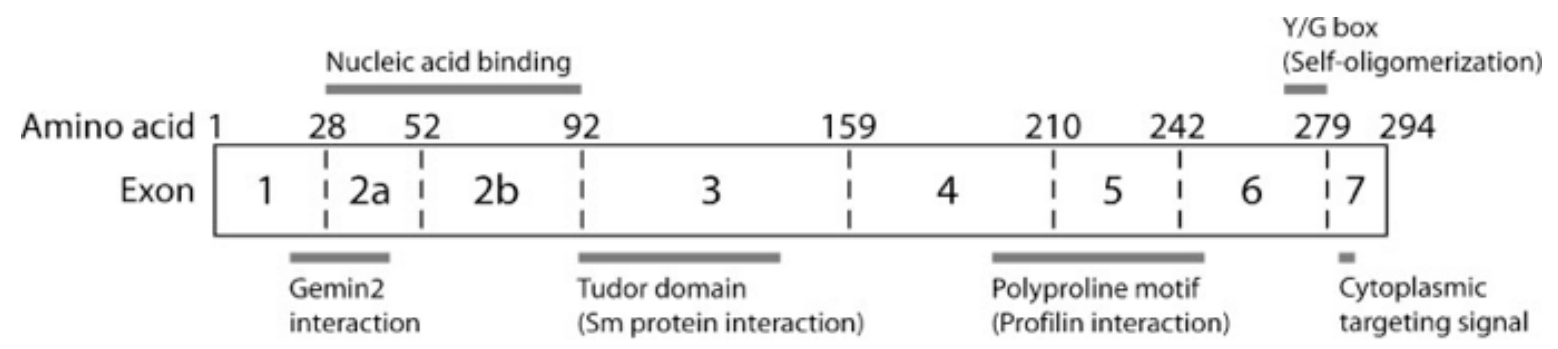

Figure 2: Schematic diagram of SMN showing coding exons and the relative localization of selected domains with known functions. In SMN2 exon 7 is spliced out resulting in truncated protein lacking the C-terminal- most 16 amino acids ( (Briese et al 2005), p 947; reproduced with kind permission from John Wiley and Sons).

drosophila melanogaster, caenorhabditis elegans, and schizosaccharomyces pombe, indicating that SMN is essential for viability of all eukaryotic organisms (Miguel-Aliaga et al 1999; Hannus et al 2000; Paushkin et al 2000; Wang and Dreyfuss 2001). One central question around this protein is why defects in a ubiquitously expressed protein have such a selective effect on motor neurons and corresponding muscles.

The C-terminal region of the SMN-protein contains a region for self-oligomerisation encoded by exon 6, which contains numerous tyrosin-glycin pairs (Lorson et al 1999). This is flanked by a central evolutionary highly conservative tudor domain, encoded by exon 3, which contains 53 amino acids and is important for the interaction between SMN and the Sm-proteins (Bühler et al 1999). Further interaction domains and a schematic illustration of the SMN-protein are shown in Figure 2.

Within one cell SMN can be found in the cytoplasm as well as in the nucleus (Liu and Dreyfuss 1996). The distribution of SMN in the cytoplasm appears diffuse in all cells studied. Only in muscle cells is SMN existent in large cytoplasmic aggregates (Liu and Dreyfuss 1996) (Burlet et al 1998). In the nucleus SMN appears as 0,1-1 $\mu \mathrm{m}$ large, dot-like structures. These structures were often found to colocalize with coiled bodies and were therefore termed gems (gemini of coiled bodies). The name coiled bodies has been recently replaced by the name cajal bodies (Gall et al 1999). Cajal bodies are known to be rich in factors involved in the transcription and processing of many types of nuclear RNAs. The close interaction of gems with cajal bodies indicates that gems are also involved in RNA-processing (Liu and Dreyfuss 1996). Beside the localization in gems SMN is also directly localized in cajal bodies in cultured cells and primary neurons (Carvalho et al 1999). In HeLa cells the assembly of the coiled bodies is disrupted due to the depletion of SMN (Girard et al 2006). Furthermore, the group of Carvalho could show that SMN in cajal bodies colocalize with small nuclear ribonucleoproteins (snRNPs). In this study the majority $(>85 \%)$ of cells studied contained SMN only in cajal bodies, while no gems could be identified (Carvalho et al 1999). Depending on the tissue SMN is expressed in different amounts (Coovert et al 1997) (Burlet et al 1998). Particularly high levels of the protein are found in the spinal motor neurons, apparently the most profoundly 
affected cells in SMA patients. Furthermore, different studies in human tissue (muscle, heart, kidney and brain) show a clear reduction of SMN-expression after birth (Burlet et al 1998). Interestingly, it is found that the intracellular distribution changes during the normal CNS-development. There is a shift from SMN being localized more in the nucleus during early stages of development towards an accumulation in the cytoplasm, especially in axons of motor neurons (Giavazzi et al 2006).

The amount of SMN is reduced in all reviewed tissues of SMA patients (Burlet et al 1998), with patients with SMA type I having smaller amounts of SMN protein than type II or type III patients (Coovert et al 1997) (Lefebvre et al 1997) (Burlet et al 1998). The spinal cord, with an almost complete absence of FL-SMN protein in type I patients, is especially affected, while the amount of SMN in lymphocytes and muscle tissue is only moderately reduced. Although in SMA mostly lower motor neurons are affected, a reduction in all reviewed tissues is detectable (Jablonka et al 2007). However SMA patients develop in the first line motor neuron degeneration and muscular atrophy (Jablonka et al 2007). In order to shed light on the selective effect of SMN on the nervous system several groups studied in particular the distribution of SMN in motor neurons. Béchade et al (1999) could for the first time demonstrate that SMN is located in the proximal part of dendrites, where it is associated with microtubules. One year later, another research group also came to the conclusion that the SMN is associated with elements of the cytoskeleton in spinal dendrites and axons, in particular during the early postnatal development (Pagliardini et al 2000). The discovery of SMN in axonal compartments led to the assumption that SMN is actively transported. Recent studies showed granular accumulations of SMN in axons of motor neurons. They demonstrated that the transport of SMN over longer distances is microtubules-dependent, while for shorter distances microfilaments are required (Zhang et al 2003). SMN is also found in the growth cones of motor neurons (Rossoll et al 2003).

\subsubsection{The SMN-Complex}

SMN is the central component of a large oligomeric complex, the so-called SMN-complex (Meister et al 2001) (Gubitz et al 2004). Already in 1996 Liu and Dreyfuss showed that SMN binds amongst others to itself, to the RGG-rich region of hnRNP U, and to fibrillarin. One year later this group identified the SMN interacting Protein1 (SIP-1), which was later termed gemin2. Until now seven more gemins have been identified. Figure 1 shows a scheme of all seven interacting proteins called gemin 2-7.

This complex has been postulated to function as an "assemblysome" important for snRNP biogenesis and pre-mRNA splicing, which will be described in the next section. The binding partners of the SMN-complex can also appear independently from each other. A recent study showed that gemin2 forms a complex with SMN including no other gemin proteins. This leads to the assumption that the pair SMN-gemin2 is the smallest available subunit. Overall a multitude of other proteins has been identified, which directly interact with SMN and/or gemins, although they are not integral components of the SMN-complex. To these proteins belong among others, the Sm- and Lsm-proteins of the small ribonucleoprotein family (snRNPs) (Liu et al 1997); (Bühler et al 1999) (Friesen and Dreyfuss 2000), 


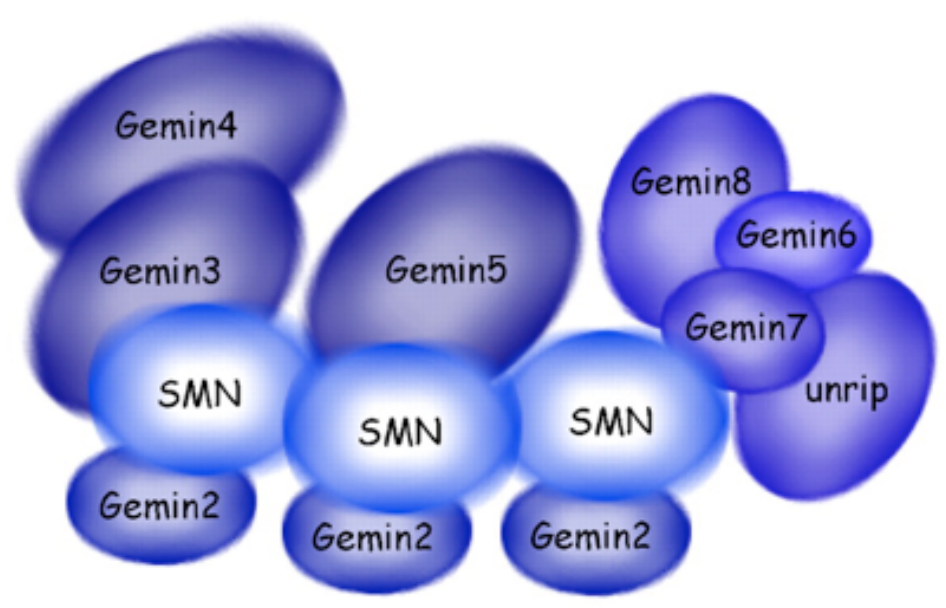

Figure 3: Schematic illustration of the SMN-complex with known components (taken from Carissimi et al 2006). SMN is interacting directly with gemin2, gemin3, gemin4 and gemin5 and gemin7 (Liu et al 1997); (Charroux et al 2000) (Gubitz et al 2004), while gemin4 binds over gemin3 (Charroux et al 2000). For the interaction of gemin6 with SMN-complex is Gemin7 required. Gemin8 binds to Gemin6 and Gemin7 on the multiprotein complex ( (Carissimi et al 2006), p. 8134; reproduced with kind permission from the author).

the helicase A (Pellizzoni et al 2001) and hnRNP Q (Mourelatos et al 2001).

The exact implication of these interactions remains to be determined. However the knowledge of these interactions may shed light on additional neuron specific functions of SMN, which may explain why reduced SMN levels have relatively little impact on cells other than motor neurons.

\subsubsection{The Role of SMN in SnRNP Biogenesis and pre-mRNA Splicing}

The most extensively documented function of the SMN has been the so called housekeeping role in providing small ribonucleoproteins, which are the main components of the spliceosome. One essential step of posttranscriptional processing of the pre-mRNA to mature mRNA is the splicing of pre-mRNA in the nucleus before being exported to the cytoplasm. During splicing the noncoding introns are removed from the pre-mRNA and the proteinencoding exons are linked to each other. This process is catalyzed by the spliceosome. The main components of the splicesomes are U snRNPs (uridine-rich small nuclear ribonucleoproteins) (Will and Lührmann 2001). Each snRNP contains seven Sm-proteins plus one or two small nuclear RNAs (snRNA U1, U2, U4/U6 and U5). The role of the SMN-complex in the assembly of splicesomal U snRNPs U1, U2, U4/U6 and U5 in the cytoplasm has been studied in detail (Fischer et al 1997); (Selenko et al 2001); (Jablonka et al. 2002); (Winkler et al 2005); (Kolb et al 2007). The SMN-complex builds the U snRNPs by loading the Sm-proteins in a well defined order onto the U snRNA (Pellizzoni, 2007). In this 


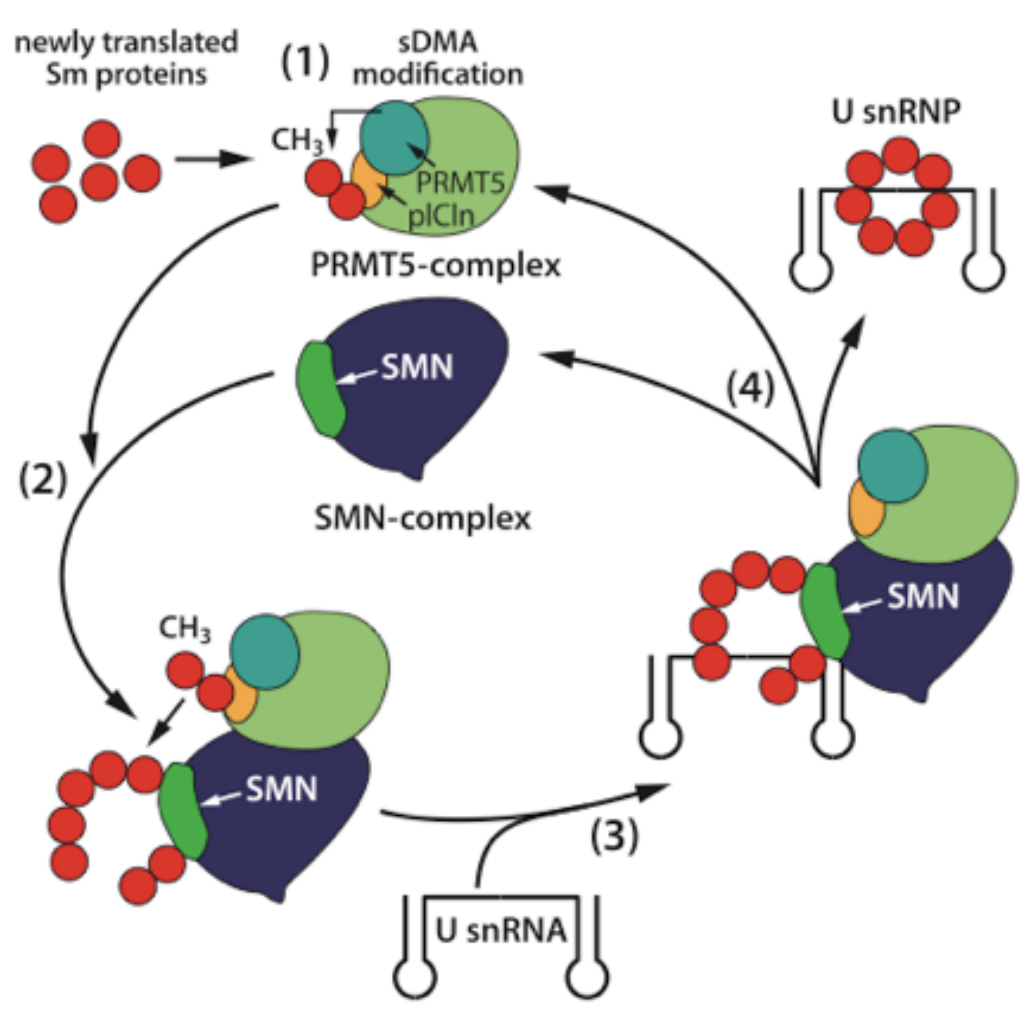

Figure 4: The mode of action of the SMN and PRMT complexes. The Sm-proteins are newly synthesized by the cell and bind to the PRMT5-complex (1). This adds methyl groups to the Smproteins, which cause their handing-over to the SMN-complex (2). The SMN-complex subsequently transfers the Sm-proteins to a nuclei acid, called U snRNA (3), thereby forming U snPNP, a subunit of the spliceosome. SMN- and PRMT5-complexes may then enter into a new cycle (Fischer et al. 1997, p. 750; reproduced with kind permission from the author).

function the SMN-complex is strictly controlled by a further protein assembly called the PRMT5-complex. Figure 4 shows the sequential course of this clustering reaction towards U snRNPs.

This process takes place in the cytoplasm. The snRNPs are then imported to the nucleus, where they are often found together with SMN-complexes in cajal bodies, where they undergo further maturation processes before they take up their function in pre -RNA splicing.

The role of SMN in snRNP biogenesis and pre-mRNA splicing has been most extensively documented (Meister et al 2000; Hannus et al 2000). However, it still remains unknown whether SMA and the motor neuron phenotype are a direct consequence of a disruption in snRNP biogenesis and pre-mRNA splicing.

A defect in a function as universal as snRNP biogenesis and pre-mRNA splicing is likely to affect all tissues equally. There are basically three schools of thought to explain why defects in a ubiquitously expressed protein may have such a selective effect on motor neurons. 
(i) Considering that low levels of SMN lead to a general defect of mRNA splicing, the tissue-specific nature of SMA could be explained by the fact that motor neurons simply have lower tolerance for depleted SMN levels, being large, high-energy requiring cells. However, a lack of an adverse effect on other large, high-energy requiring cells, such as cortical motor neurons and sensory neurons makes this a questionable hypothesis.

(ii) Another possibility would be that the unique sensitivity of affected motor neurons in SMA is a result of aberrant splicing of one or more RNAs, which are critical for the appropriate functioning of these cells. However, such RNAs have yet to be identified.

(iii) The SMN may have additional motor neuron specific functions besides its role in snRNP biogenesis and pre-mRNA splicing. Studies confirming this school of thought will be discussed in the next section.

\subsubsection{Motor Neuron Specific Function of SMN}

The main feature distinguishing neurons from other cell types is that they possess dendrites and axons that convey messages from one neuron to another or target muscle cells by chemical and electrical processes. This feature implies that cargo has to be transported over long distances in order to secure sustainability and growth of neurons. Several lines of evidence support additional neuron-specific functions of SMN. The hypothesis that SMN has a neuron-specific function firstly emerged from the observations demonstrating accumulation of SMN protein in the axon and growth cones of neurons specifically in cells in vitro (Fan and Simard 2002) and anterior horn cells in vivo (Tizzano et al 1998). These observations have been fostered by experiments identifying the presence of SMN-containing granules within the neurites of chick cortical neurons and rat spinal motor neurons (Figure 5 ), that associate with microtubules and exhibit bidirectional movement between the cell body and the growth cone (Zhang et al 2003) .

Moreover, it is well established that SMN can bind RNA (Lorson and Androphy 1998) (Bertrandy et al 1999) and ribonucleoprotein particles (Jones et al 2001); (Liu and Dreyfuss 1996); (Mourelatos et al 2001).

These findings lead to the assumption that SMN may be involved in the transport of specific mRNAs to the growth cone in response to local cues during development. Rosoll and colleagues reported that SMN and its binding partner hn-RNP $\mathrm{R}$ modulate axon growth cones. They finally discovered that SMN and its hnRNP are involved in the processing and localization of $\beta$-actin mRNA to the growth cones of developing motor neurons (Rossoll et al 2003). Reduced growth cone size, lower $\beta$-actin levels and shorter neurites in primary motor neurons from SMA mice add further weight to this line of thought. The role of actin in the SMA disease will be discussed in a following section.

Recent studies could show that SMN directly binds to the alpha-subunit of the vesicle coat protein 'coat protein I' (COPI). This subunit, alpha-COP, is Golgi associated and co-immunoprecipitates with SMN, small nuclear ribonucleoportein-associated assembly factors and $\beta$-actin mRNA. This observation leads to the proposal that neurons utilize 


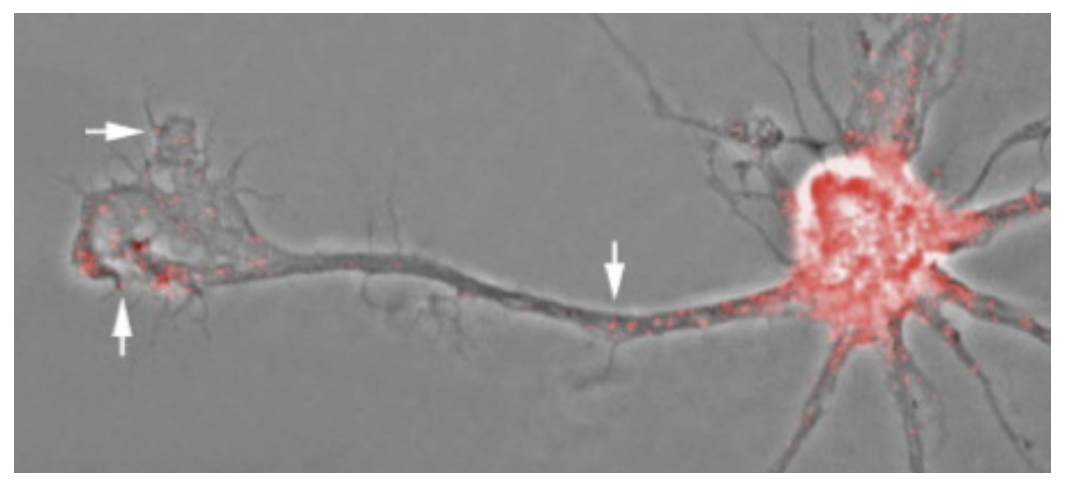

Figure 5: A chick cortical neuron stained with an antibody against SMN showing abundant nucleocytoplasmic staining as well as the presence of granules (arrows) within neurites and the growth cone. The granules, RNP particles, are found associated with microtubules, indicating movement along the axon. This supports the idea of a motor neuron specific function of the SMN protein ( (Monani 2005), p. 889; reproduced with kind permission from Elsevier).

the Golgi associated COPI vesicles to deliver cargos necessary for motor neuron integrity and function (Peter et al 2011). Thus, another study adds further weight to the hypothesis that mutated SMN interferes with the transport of cargo in the axon, which might provide an explanation of the neuron-specific nature of SMA.

\subsection{Mouse Models of SMA}

Animal models can shed considerable light on the pathogenesis and mechanisms of their respective human disease. Since the SMN mutations were first identified as responsible of SMA, numerous organisms have been manipulated in order to generate animal models of SMA. In the following, the approach leading to the mouse model we used for our experiments will be explained. Several problems had to be circumvented before obtaining a suitable mouse model.

The identification of the murine homolog of the SMN gene (Smn) (DiDonato et al 1997) made it possible to knock it out (Schrank et al 1997). However, humans are the only species with an SMN2 gene and all SMA patients carry at least one intact SMN2 gene. A complete knock out in mice, in other words a complete lack of the SMN protein, is embryonically lethal and therefore did not result in a useful mouse model, but provided evidence that Smn is an essential gene (Schrank et al 1997). This is not surprising, given the fact that in SMA patients the SMN1 gene is also deleted or mutated but the SMN2 gene is still producing small amounts of FL-SMN protein.

One approach taken to overcome the embryonic lethality in Smn -/- mice was to introduce the SMN2 gene into this genetic background (Monani et al 2000). This strategy showed that the phenotype depends on the SMN2 transgene copy number. The introduction of eight copies of SMN2 completely rescued the SMA phenotype, two copies resulted in SMA mice that die at 5 days of age (Hsieh-Li et al 2000); Monani et al. 2000) and one 
copy was embryonically lethal (McGovern et al 2008). The most abundant gene product of SMN2 is called SMN $\Delta 7$, its name describing the fact that the resulting protein is missing the information of exon 7 due to alternative splicing.

To test whether SMN $\Delta 7$ is beneficial or detrimental in SMA, Le and colleagues (Le) et al 2005) created transgenes expressing this SMN isoform and introduced them into the severe SMA genetic background with two SMN2 copies.

They could demonstrate that an increase in SMN $\Delta 7$ has a positive effect on the survival of SMA mice by extending their lifespan from $5.2 \pm 0.2$ to $13.3 \pm-0.3$ days (Le et al 2005). This phenotype with specific motor defects, and mice that survive up to 14 days turned out to be a very suitable model for experiments and were therefore also used in our experiments.

Our mouse lines were kindly provided by Dr. A. Burhes and the Ohio State University. The experimental mice were obtained by breeding pairs of SMA carrier $(S m n+/-$; SMN2+/+; SMN $\Delta 7+/+$ ) on a FVB/N background.

\subsection{Neuro Muscular Junction (NMJ) Pathology in SMA}

\subsubsection{Synaptic Vesicles}

Synaptic vesicles allow the communication between neurons and other cells through releasing neurotransmitter, at the NMJ acetylcholine, into the synaptic gap, as chemical response to the electrical impulse arriving at the nerve terminal. Vesicles are constantly recreated and grouped into three pools: the readily releasable pool, the recycling pool, and the reserve pool. The vesicles of the readily releasable pool are docked to the cell membrane, making them the first group of vesicles to be released on stimulation. The recycling pool is defined as those vesicles that maintain release upon (physiological) moderate stimulation. The majority of vesicles (typically $\sim 80-90 \%$ ) belong to the reserve pool from, which release neurotransmitter only during intense stimulation (Rizzoli and Betz 2005). Figure 6 illustrates this three-pool model.

Several functional studies at the NMJ in SMA mice lead to the question whether there is a disruption regarding synaptic vesicles in SMA mice. Kong and colleagues measured a two-fold reduction of the evoked endplate currents (EPCs). The EPCs depend on the number of fused vesicles and the muscle response to the transmitter released from a single vesicle. The spontaneous miniature EPC (MEPC), defined as muscle response to one single vesicle, was found to be normal, indicating that a decreased number of fused vesicle leads to the reduction of the EPCs (Kong et al 2009).

In agreement with this study it was found that the kinetics of the postsynaptic potentials are slowed and evoked neurotransmitter release is decreased by approximately $55 \%$ in Transverus Abdominus (TVA) muscle (Ruiz et al 2010). Indeed electron microscopy images of the NMJ in TVA showed that individual synaptic vesicles within presynaptic terminals had normal diameters and morphology, but overall density of synaptic vesicles within the presynaptic terminal area was reduced by $56 \%$, while the number of docked 


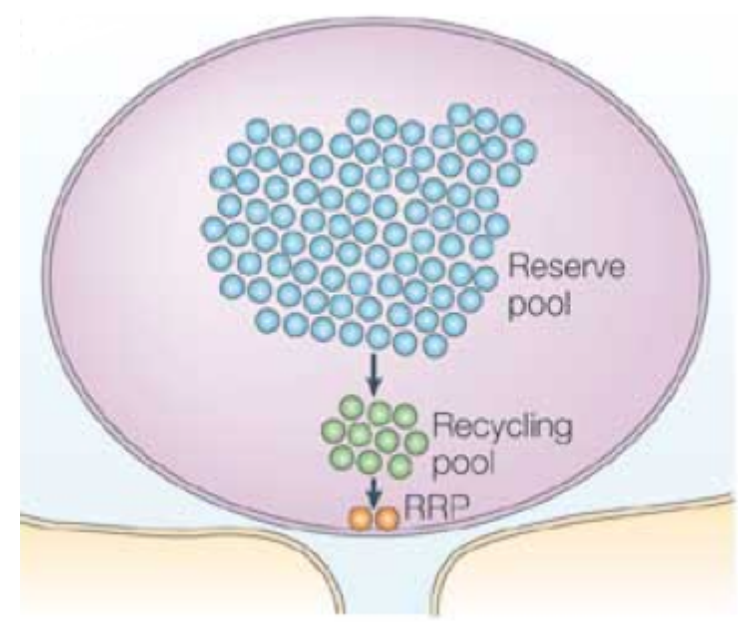

Figure 6: "The classic three-pool model. The reserve pool makes up $\sim 80-90 \%$ of the total pool, and the recycling pool is significantly smaller $(\sim 10-15 \%)$. The readily releasable pool (RRP) consists of a few vesicles $(\sim 1 \%)$ that seem to be docked and primed for release". Figure and caption from (Rizzoli and Betz 2005), p. 58; reproduced with kind permission from Nature Publishing Group)

vesicles, defined as those within $20 \mathrm{~nm}$ of the membrane, was only reduced by $32 \%$ (Kong et al (2009). In contrast, in diaphragm no significant difference in vesicle number was found (Kariya et al 2009).

To expand the perspective of the amount and distribution of synaptic vesicles (SVs) in SMA mice, we explored both total area of the terminal covered by SVs and the SVs spatial organization through fluorescent microscopy. First we undertook this study in TVA, a postural muscle of the anterior wall innervated by lower intercostal nerves. This muscle is known to be severely affected in the disease.

Additionally, we studied SVs in Levator Auris Longus muscle (LAL) from the dorsal surface of the head, innervated by the facial nerve. These studies allowed us to quantify preand postsynaptic pathology in muscle groups from two anatomical regions of the mouse and to compare pathologies in predominately slow-twitch (TVA) versus fast-twitch (LAL). Two further characteristics render the LAL muscle an interesting object of study: First, the LAL has two constituent muscle bands, among which the caudal band is known to be more affected in the disease than the rostral band (Murray et al 2008). After a comprehensive comparison between the rostral and the caudal bands, it was shown that the two bands differ in their "Delayed Synapsing" (DeSyn) and "Fast Synapsing" (FaSyn) characterictis (Murray et al 2008). It is therefore likely that selective vulnerability is due to the FaSyn characterictics, dominant in the caudal band. These two classes, DeSyn and FaSyn, differ in the focal AChRs clustering, the alignment of presynaptic nerve with AChRs and the alignment of schwann cells. In FaSyn muscles, this focal organization process is achieved in less than 1 day, whereas in DeSyn muscles up to 5 days are required (Murray et al 2008). Experimentally these two classes can be distinguished by their reaction to paralysis with botulinum toxin A. While NMJs conforming to a DeSyn phenotype have been shown 
to undergo dramatic collateral sprouting, FaSyn NMJ remains largely unaffected (Murray et al 2008).

Second, postsynaptic terminals have been described to mature almost at the same pace as in control mice (Murray et al 2008). This allows us to assess the question to what extent pre-and postsynaptic phenotypes are interrelated by proving whether the pathology regarding SVs found in TVA is also found in LAL.

The question how deficiency of SMN protein can contribute to the observed abnormalities of synaptic vesicles will be addressed in the discussion part.

\subsubsection{Mitochondria}

Mitochondria are organelles of elaborate structure, that in addition to supplying cellular energy and producing reactive oxygen species (ROS) have significant roles in calcium homeostasis and apoptosis. At the presynaptic side they regulate intraterminal $\mathrm{Ca}^{2+}$ levels, providing an especially important buffering action during trains of action potentials (David and Barrett 2000). Exploring the neurotransmission of severe SMA revealed that asynchronous neurotransmitter release is increased by $\sim 300 \%$ compared to the wild type (Ruiz et al 2010).

Presynaptic terminals release neurotransmitter at rest (spontaneous release), upon a single action potential (synchronous evoked release), and during intraterminal $\mathrm{Ca}^{2+}$ accumulation resulting from prolonged electrical stimulation (asynchronous release). Therefore, the mentioned increase of asynchronous release indicates an anomalous augmentation of intraterminal bulk $\mathrm{Ca}^{2+}$ in SMA mice. A possible explanation for this augmentation is a decreased $\mathrm{Ca}^{2+}$ reuptake by mitochondria during trains of action potentials (Ruiz et al 2010 .

Mitochondria dysfunction is known to be involved in many neurodegenerative diseases, however little is known about the role of mitochondria in SMA pathogenesis. Mitochondria are briefly mentioned in two electron microscopy (EM) studies on P14 SMA mice. The study in diaphragmatic muscle showed that presynaptic mitochondria are decreased in size but not in numbers (Kariya et al. 2008). In contrast, another research group demonstrated in Tibiales Anterior muscle a reduced density of mitochondria, while mitochondrial morphology was normal (Kong et al 2009).

To study the density, reliability, and spatial distribution of mitochondria in Transversus Abdominal muscle (TVA) at P14 under the confocal microscope, we used Mito Tracker , a cell-permanent fluorescent dye that is sequestered by functioning mitochondria. Moreover we explored the spatial relationship between Mito Tracker spots and SV clusters; reflecting the two main organelles of the presynaptic compartment, for which actin serves as a track for short-range transport (Langford 2002).

\subsubsection{F-Actin}

Actin is one of the most abundant proteins in eukaryotic cells. Actin is the monomeric subunit of microfilaments known as globular actin (G-actin). G-actin subunits assemble 


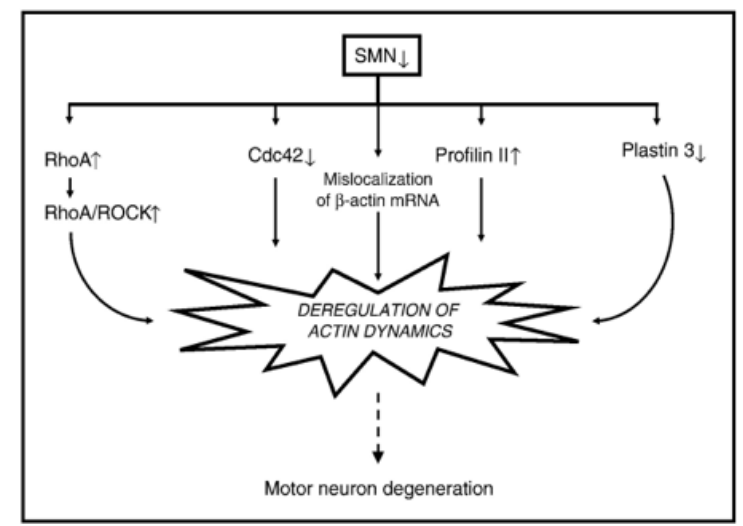

Figure 7: Simplified model of how SMN depletion impacts the regulators of actin cytoskeletal dynamics and thereby causes in motor neuron degeneration ( (Bowerman et al 2009) p. 72; reproduced with kind permission from author).

into long filamentous polymers called F-actin.

In neurons, actin-filament plays an important role in multiple functions such as axon initiation, growth, guidance, and branching during neuron development. In order to secure sustainability in neurons, cargo has to be transported over long distances. The "dual transport model" was proposed in which microtubule-based motors ensure long-range axonal transport, whereas short-range movement of organelles such as vesicle and mitochondria at nerve terminals and subcortical plasma membrane regions depends primarily on actin-based myosin (Langford 2002). In addition to these functions, the F-actin-based network (Hirokawa and Takeda 1998) may participate in creating a scaffold for SV clustering, and/or in supporting ordered vesicle mobility. Moreover, it has been suggested that F-actin anchors synaptic vesicles to AZs by a labile link formed with synapsin, a vesicle protein (De Camilli et al 1990); Greengard et al. 1993)

Several lines of evidence suggest that a deregulation of actin plays an important role in SMA pathogenesis. SMN with its binding partner hnRNP $\mathrm{R}$ has been shown to interact with $\beta$-actin mRNA and mediates the transport along the axon. A decrease in actin protein content in growth cones of SMN-deficient motor neurons in culture and reduced axon growth adds further weight to this line of thoughts (Rossoll et al 2003). Additional SMNdeficient PC12 cells have increased levels of neuronal profilin IIa protein, accompanied by a decrease in levels of plastin3 (Bowerman et al 2009). This is leading to an inappropriate activation of the Rho/ROCK pathway. RhoA is a small GTPase that plays an important role in the regulation of actin cytoskeletal dynamics, which is essential for a balanced equilibration between actin depolymerization and filament stabilization (Luo et al 1997). In neurons, by signaling through various pathways, RhoA mediates neuronal growth, formation, polarization, regeneration, branching, pathfinding, guidance, and retraction Govek et al 2005).

Given that actin might play a key role in SMA pathogenesis, we wanted to explore further its content and distribution relative to SVs in TVA motor terminals of SMA mutant 
mice. F-actin was revealed by fluorescent Phalloidin-Alexa 647, which binds to all isoforms of F-actin, but not to monomeric actin (Wulf et al 1979).

\subsubsection{The Questions and Objectives of this Study}

Previous research about spinal muscular atrophy using animal models provided important insights regarding the pathomechanisms of this disease.

Rosoll and colleagues (2003) could show in motor neurons in culture that SMN together with its binding partner heterogeneous nuclear ribonucleoprotein (hnRNP) R interacts with the $\beta$-actin mRNA and mediates its transport along the axon. Among others, this study provided evidence for a motor neuron specific function of SMN and indicated that actin plays an important role in SMA pathogenesis.

Short-range movements of organelles, such as vesicles and mitochondria, belong, among others, to the processes mediated by actin in motor neurons (Langford 2002). Moreover the F-actin-based network may participate in creating a scaffold for synaptic vesicle clustering (Hirokawa et al 1989) and it has been suggested that F-actin anchors synaptic vesicles to AZs by a labile link formed together with synapsin, a vesicle-associated protein (De Camilli et al. 1990; Greengard et al. 1993).

Functional studies at the NMJ of SMA mice revealed that evoked neurotransmitter release is decreased by approximately 55\% in TVA muscle, indicating a decreased number of fused vesicles. On the other hand asynchronous release is increased by $\sim 300 \%$ due to an anomalous augmentation of intraterminal bulk $\mathrm{Ca}^{2+}$ in SMA mice. A possible explanation of this augmentation is a decreased $\mathrm{Ca}^{2+}$ reuptake by mitochondria during trains of action potentials (Ruiz et al 2010).

The work described here has the aim to explore the amount and organization of Synaptic Vesicles (SVs), mitochondria, and actin in nerve terminals of SMA mice compared to controls, in order to provide morphological evidence for the observed disturbed neurotransmission at the NMJ of SMA mice. Moreover, it is my aim to gain insight into the question whether a deregulation in actin dynamics provides a possible link to abnormalities observed in SMA pathogenesis.

All experiments regarding SVs, mitochondria and actin were done with TVA muscle of 14 days (P14) old mice in a mouse model of a severe form of this disease.

The study about SVs has been extended in the following aspect:

To get insight into the maturation process in SMA disease, the distribution of SVs were studied additionally in seven days (P7) old mice, both in TVA and levator auris longus (LAL) muscle. The LAL consists of a rostral and a caudal band. The caudal band is known to be more affected than the rostral band in the disease (Murray et al 2008). This allowed me to study SVs for three different muscle conditions at P7 and P14. Another characteristic of the LAL is that the postsynaptic terminals have been described to mature almost at the same pace as in control mice, while the presynaptic morphology shows abnormalities in P5-P6 SMN deficient mice (Murray et al 2008). It was my aim to test in LAL muscle whether SVs abnormalities occur also in the absence of a postsynaptic pathology to gain 
insight into the question how much pre- and the postsynaptic phenotypes are interrelated in SMN deficient mice.

In particular the following aspects will be quantified:

1. Synaptic Vesicles

(a) Total area of SV clusters

(b) Mean area of a single SV cluster

(c) Number of SVs clusters

2. Mitochondria

(a) Total area of Mito Tracker spots

(b) Mean area of a single Mito Tracker spots

(c) Number of Mito Tracker spots

3. Organization of Synaptic Vesicles and Mitochondria within the nerve terminal

4. Amount and distribution of F-Actin related to SVs clusters. 


\section{Chapter 2}

\section{Materials and Methods}

\subsection{Materials}

\subsubsection{Mouse Model}

SMA mouse lines were kindly provided by Dr. A. Burghes (Ohio State University, Ohio, USA) and are presently available in the Animal House in Seville. Experimental mice were obtained by breeding pairs of SMA carrier mice $(\mathrm{Smn}+/-; \mathrm{SMN} 2+/+; \mathrm{SMN} \Delta 7+/+)$ on a FVB/N background. Mice were housed, handled, and bred in accordance with the regulations of the E.U. for animal care and use.

\subsubsection{Equipment}

\begin{tabular}{|l|l|}
\hline Genotyping & \\
\hline Centrifuge & Eppendorf 5415 D \\
Multipipette & Eppendorf plus \\
Thermocycler & Biometra TGradient \\
UV Transilluminator & Vpland M 15 \\
\hline \hline Surgery & \\
\hline Mayor scissors & F.S.T stainless (Germany) 14060-11 \\
Forceps & F.S.T stainless (Germany) 14022-12 \\
Microsurgical scissors & Nopa CE Germany Stainless AC778/02 \\
Surgical Blade & Steriler CE 0434 \\
\hline \hline
\end{tabular}




\begin{tabular}{|l|l|}
\hline Immunocytochemistry & \\
\hline Microscope Slides & Menzel Glaeser \\
Coverslip & Menzel Glaeser \\
Orbital Shaker & Biosan 0S-20 \\
Plates & Cellstar \\
Vapor Pressure Osmometer & Wescor 5500 \\
pH Meter & Crison Basicco \\
Scale & Mettler PJ360 \\
\hline \hline Microscopy & \\
\hline Stereoscopic Zoom Microscope & Nikon SMZ1500 \\
Confocal Laser Scanning Microscope & Olympus FV 1000 \\
\hline \hline Image Analysis & \\
\hline ImageJ & www.macbiophotonics.ca/downloads.htm \\
\hline
\end{tabular}

\subsubsection{Genotyping}

\begin{tabular}{|l|l|}
\hline Genotyping & \\
\hline Alkaline Lysis Reagent & (25mM NaOH; 0.2 mM EDTA $)$ \\
Neutralization Reagent & $40 \mathrm{mM}$ Tris-HCL adjusted to pH $)$ \\
Ethidium Bromide & Sigma 160535 \\
\hline \hline Primers & \\
\hline Neo B Primer & Sigma VC00021 \\
A2R Primer & Sigma 700023 \\
A2F Primer & Sigma 700025 \\
\hline \hline Oligonucleotides & \\
\hline dNTPs & Invitrogene 10043 \\
\hline \hline Enzymes & \\
\hline Taq 5U & Biotools 10043 \\
\hline \hline Solution and Buffers & \multicolumn{1}{|l|}{ Biotols 10044 } \\
\hline PBS Buffer 10X & 192 mM Glycine, $0.1 \%$ SDS, 25mM Tris-HCl, pH 8.3 \\
Electrophoresis Buffer & 0.125 M Tris-HCl, pH $6.8,4 \%$ SDS, 0.15 M DTT \\
SDS-Sample Buffer & $20 \%$ Glycerol, 0.01\% Bromphenol blue \\
\hline
\end{tabular}

\subsubsection{Immunocytochemistry}

\begin{tabular}{|l|l|}
\hline Chemicals & \\
\hline Paraformaldehyde (PFA) & Sigma-Aldrich, CAS 30525 \\
Phosphate Buffered Saline (PBS) & Sigma-Aldrich, EC 231-834-5 \\
Albumin from Bovine Serum (BSA) & Sigma-Aldrich, EC 232- 936- 2 \\
Glycine & Sigma-Aldrich, EC 200-2722 \\
Slowfade Gold Antifade Reagent & Invitrogen 586012 \\
\hline
\end{tabular}




\begin{tabular}{|c|c|c|c|}
\hline Antibody & Concentration & Type & Reference \\
\hline Primary antibody & $1: 500$ & polyclonal & Invitrogen 139103 \\
\hline $\begin{array}{l}\text { Anti-VAChT } \\
\text { Primary antibody }\end{array}$ & 1.500 & rabbit & DSHB 149_81791 \\
\hline Anti-SV2 & & mouse & \\
\hline Secondary antibody & $1: 500$ & polyclonal & Invitrogen A11029 \\
\hline Alexa 488 & & donkey & \\
\hline $\begin{array}{l}\text { Secondary antibody } \\
\text { Alexa } 647\end{array}$ & $1: 500$ & $\begin{array}{l}\text { polyclonal } \\
\text { donkey }\end{array}$ & Invitrogen A21236 \\
\hline Dye & "Concentration & Type & Reference \\
\hline $\begin{array}{l}\text { Mito Tracker Orange } \\
\text { CMX Ros }\end{array}$ & $400 \mathrm{nM}$ & $\begin{array}{l}\text { thiol-reactive } \\
\text { chlormethyl } \\
\text { moiety }\end{array}$ & Invitrogen M7510 \\
\hline $\begin{array}{l}\alpha \text {-Bungarotoxin } \\
\text { Alexa Fluor } 647\end{array}$ & $1.25 \mu \mathrm{l} / \mathrm{ml}$ & snake toxin & Invitrogen L2911 \\
\hline $\begin{array}{l}\alpha \text {-Bungarotoxin } \\
\text { Rhodamine }\end{array}$ & $1.25 \mu \mathrm{l} / \mathrm{ml}$ & snake toxin & Sigma T0195 \\
\hline $\begin{array}{l}\text { Alexa flour } 647 \\
\text { phalloidin }\end{array}$ & $25 \mu \mathrm{l} / \mathrm{ml}$ & mushroom toxin & Invitrogen A22287 \\
\hline
\end{tabular}

Table 2: Summary of reagents used for immunostaining.

\section{Solutions and Buffers}

\section{Hepes solution:}

- $145 \mathrm{mM} \mathrm{NaCl}$

- $5 \mathrm{mM} \mathrm{KCl}$

- $2 \mathrm{mM} \mathrm{CaCk} 2$

- $1 \mathrm{mM} \mathrm{MgCl}_{2}$

- $15 \mathrm{mM}$ glucose

- $10 \mathrm{mM}$ Hepes.

$\mathrm{NaOH}$ was used to adjust the $\mathrm{pH}$ between 7.35 and 7.4. The osmolarity was adjusted between 300 and $310 \mathrm{mmol} / \mathrm{kg}$ by using an osmometer. 


\subsection{Methods}

\subsubsection{Genotyping}

SMA mice could be distinguished from wild type mice through clinical observation; however, all mice were genotyped for confirming their genetic characteristic.

Visual and clinical Identification of SMA The SMA mice $(\Delta 7)$ are smaller in size and appear weak and less active compared to WT mice. Further identification was done through the righting reflex test: when turned onto there back SMA mice showed some latency in righting themselves.

Marking and caudal biopsy Five days after birth each mouse received an individual identification number by cutting a fingertip. Through this mark the mice could be identified before the experiment. The PCR genotyping was done using tail DNA.

DNA Extraction To lyse the cells, the tissue samples from caudal biopsy were centrifuged for $30 \mathrm{sec}$ at $13.000 \mathrm{rpm}$ with $50 \mu$ ladded alkaline lysis reagent and then incubated, first for $30 \mathrm{~min}$ at $65^{\circ} \mathrm{C}$, followed by $15 \mathrm{~min}$ incubation at $98^{\circ} \mathrm{C}$. After lysis, the samples were placed on ice for $1 \mathrm{~min}$ and treated with $50 \mu \mathrm{l}$ Neutralizing Reagent. To separate the DNA from the rest, the samples were centrifuged for 1 min at $13.000 \mathrm{rpm}$. After centrifugation $50 \mu \mathrm{l}$ of the supernatant, containing the DNA, were pipetted and put into a clean tube.

PCR The polymerase chain reaction (PCR) is a technique to amplify a particular DNA sequence. With this technique we could amplify a DNA sequence identifying either the wild type gene or SMA variant. The method relies on thermal cycling, consisting of cycles of repeated heating and cooling of the reaction for DNA melting and enzymatic replication of the DNA. During the first step the DNA physically separate into two strands through a high temperature around $90^{\circ} \mathrm{C}$. At a lower temperature, around $50^{\circ} \mathrm{C}$, the specific primers can complementarily bind to the DNA. Starting from the primer, at a temperature around $65{ }^{\circ} \mathrm{C}$, each strand is then used as the template in DNA synthesis by the heat stable DNA polymerase (Taq Polymerase) to selectively amplify the target DNA. Building blocks for the synthesis are the desoxyribonucleoside triphosphates (dNTPs). Repeating this cycle, in our case 35 times, leads to an exponential amplification of the target DNA. The protocol we used is based on a single tube reaction with 3 primers, two located in the WT gene $(\mathrm{A} 2 \mathrm{~F}$ and $\mathrm{A} 2 \mathrm{R})$ region and one in the neomycin cassette present in $\mathrm{KO}$ mice. 


\begin{tabular}{|l|l|l|}
\hline PRIMER & MER & Sequence 5'-3' \\
\hline NeoB & 21 & GCA GCT GTG CTC GAC GTT GTC \\
\hline A2R & 25 & CCT TAA AGG AAG CCA CAG CTT TAT C \\
\hline A2F & 21 & GCT CTT GGC AAC CCT ACT GTC \\
\hline
\end{tabular}

Table 3: Primer Sequences

The reaction was done with the following components:

- $9.3 \mu \mathrm{l} \mathrm{MQ}$ water

- $4 \mu \mathrm{l} \mathrm{MgCl} 2$ (25mM)

- $2.5 \mu$ l buffer 10X (Biotools)

- $0.5 \mu \mathrm{l}$ dNTPs $25 \mathrm{mM}$ (Invitrogene)

- $0.5 \mu \mathrm{l}$ Neo B primer $10 \mu \mathrm{M}$ (Sigma)

- $0.5 \mu \mathrm{l} \mathrm{A2R}$ primer $10 \mu \mathrm{M}$ (Sigma)

- $0.5 \mu \mathrm{l}$ A2F primer $10 \mu \mathrm{M}$ (Sigma)

- $0.2 \mu \mathrm{l}$ Taq 5U/ $\mu \mathrm{l}$ (Biotools)

- $1 \mu \mathrm{l}$ DNA

Using the following PCR program: (1) $95{ }^{\circ} \mathrm{C} / 4 \mathrm{~min},(2) 95{ }^{\circ} \mathrm{C} / 1: 30 \mathrm{~min},(3) 62{ }^{\circ} \mathrm{C} /$ 1:30 min, (4) $72{ }^{\circ} \mathrm{C} / 1: 30 \mathrm{~min} ; 35 \mathrm{x}$ steps 2 to 4 , (5) $72^{\circ} \mathrm{C} / 4 \mathrm{~min}$, (6) $4{ }^{\circ} \mathrm{C} / 1 \mathrm{~h}$.

\section{Electrophoresis}

The amplified target DNA could be detected by gel electrophoresis, showing two different bands, one at 900 base pairs (bp) corresponding to the $\mathrm{KO}$ and another at $600 \mathrm{bp}$ corresponding to the WT gene. Both bands were amplified in heterozygous mice whereas in homozygote mice only one band was detectable (Fig.8)

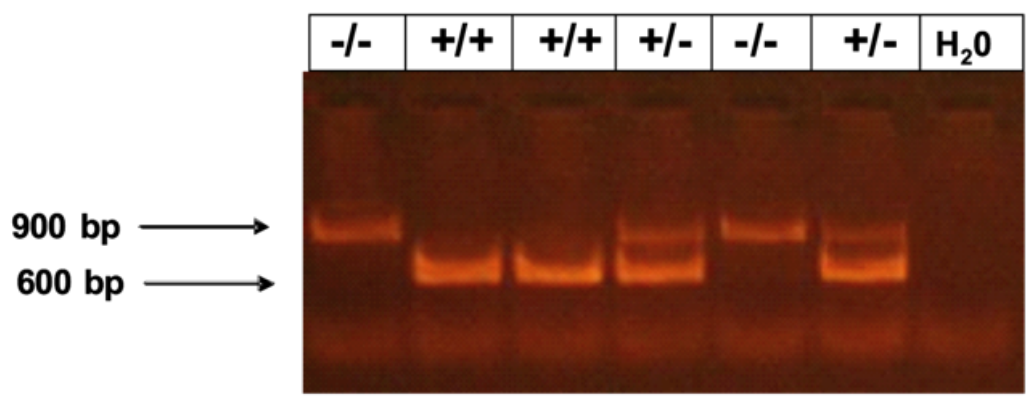

Figure 8: Electrophoresis showing null (-/-), heterozygous (+/-) and WT (+/+) genotypes with 900 bp corresponding to absence of the gene and $600 \mathrm{bp}$ to the presence of the gene. 


\subsubsection{Muscle Dissection}

Mice were sacrificed by means of $\mathrm{CO}_{2}$ and immediately exsanguinated.

\section{Transversus Abdominis (TVA)}

The TVA is the inner muscle of the abdominal wall. For an optimal penetration during immunochemistry all tissues above the TVA need to be removed carefully (Figure 9). As a first step the mouse was positioned in dorsal decubitus and the abdominal skin was opened through a midline incision and pulled to the sides. Second, the whole left hemi-abdominal muscle wall, up to the sternum, was cut out and pinned to the bottom of a $2 \mathrm{ml}$ chamber, over a bed of cured silicone rubber (Sylgard, Dow Corning). Third, the Obliquus Externus muscle and the fat tissue were removed carefully to obtain a free area of intact TVA muscle fibers with their corresponding nerve branches.

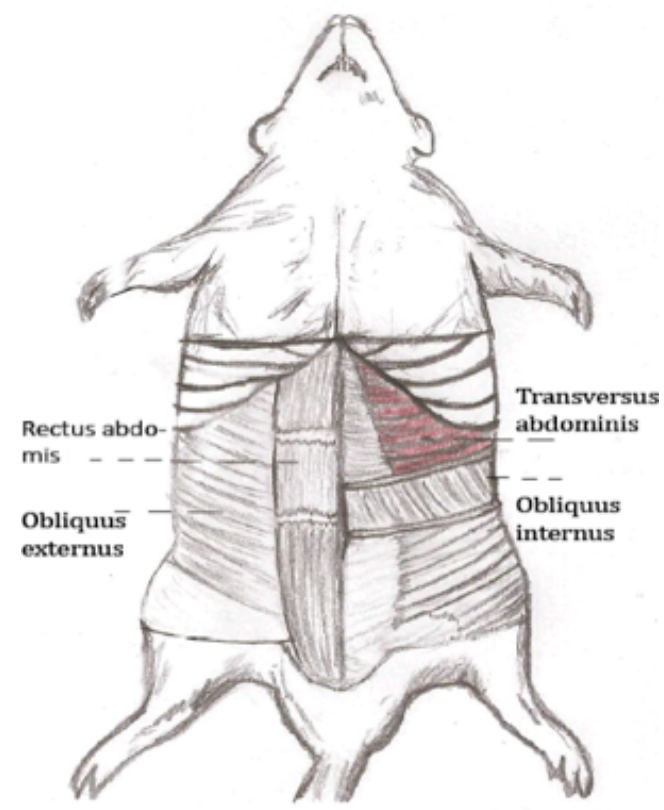

Figure 9: Abdominal muscle wall from mice. In red Transverus Abdominus Muscle (TVA) used for experiments ( self-made drawing).

\section{Levator Auris Longus (LAL)}

The LAL is located directly under the neck skin reaching from the cranial midline towards the ears (Fig. 10). For the dissection, the hair was removed by shaving the area between the left ear and the cranial midline. Second, the left neck muscle block with skin was removed and pinned upside down to the bottom of a $2 \mathrm{ml}$ chamber. Before removing several other muscles (M.Splenius Capitis, M. Capitis Post Mayor, M. Cervicoscularis) located over the LAL, the skin underneath was pulled to the side. Finally, the LAL was cleaned from fat and connective tissue. Figure 10 shows the LAL with the two constituent muscle bands (rostral and caudal). 


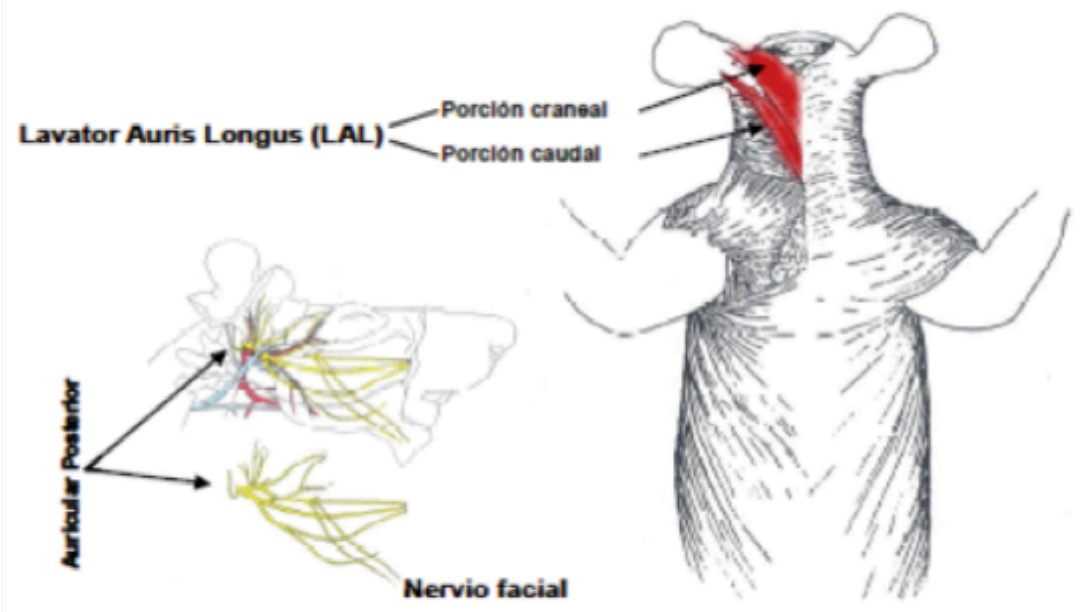

Figure 10: The Levator Auris Longus muscle LAL with two constituent muscle bands (rostral and caudal) reaching from the cranial midline towards the ears (Taken from (Greene 1935), p. 130).

\subsubsection{Immunocytochemistry and Toxin-Conjugated Labeling}

\section{Visualization of the different investigation targets}

Postsynaptic side.The endplates were labeled with $\alpha$-Bungarotoxin ( $\alpha$-BTX), a snake toxin that binds to the muscle-type nicotinic acetylcholine receptor (nAChR). $\alpha$-BTX was conjugated to either rhodamine or Alexa Fluor 647.

Synaptic Vesicles were marked by using a primary antibody, anti-VAChT, against the vesicular acetylcholine transporter. This primary antibody was visualized using a secondary antibody containing a fluorescent dye. The vesicular acetylcholine transporter VAChT is an integral membrane protein with 12 putative trans-membrane domains. VAChT translocates acetylcholine from the cytoplasm into synaptic vesicles, where it stays until release.

A second type of vesicle staining was done using a primary antibody against the synaptic vesicular transmembrane protein (SV2). This primary antibody was again visualized using a secondary antibody containing a fluorescent dye.

Mitochondria were labeled with Mito Tracker, a fluorescent dye containing a mildly thiol-reactive chlormethyl moiety. This cell-permeant probe is oxidized when it enters an actively respiring cell. Depending on the mitochondrial membrane potential Mito Tracker diffuses passively across the membrane and accumulates in active mitochondria (Poot et al 1996). Specific staining of mitochondria depends critically on the viability of the preparation. Therefore, the dissection was done as quikly as possible with a minimun of cell damage. Actin was labeled with phalloidin, a high-affinity probe for filamentous-actin 
(F-actin). The toxin phalloidin is extracted from a mushroom, amanita phalloides and conjugated to a bright, far-red-fluorescent dye, Alexa Fluor $64 \%$.

\section{The protocols}

The different protocols differ only slightly from each other nevertheless they are described completely to facilitate replication of the experiment.

\section{Synaptic Vesicles and mitochondria staining}

The muscles were dissected in hepes solution at $\mathrm{pH}$ between 7.35 and 7.4 (see section 2.3.4.3. Solutions and Buffers), followed by 40 minutes incubation with $400 \mathrm{nM}$ Mito Tracker diluted in hepes solution. After washing with hepes solution, the preparations were fixed in $4 \%$ paraformaldehyde, washed with PBS and incubated at $4{ }^{\circ} \mathrm{C}$ over night. Subsequently they were incubated with glycine $0.1 \mathrm{M}$ in PBS for $30 \mathrm{~min}$ at room temperature to bind and removes aldehydes left over from the fixation step. Subsequently muscles were permeabilized with $1 \%$ Triton X-100 in PBS. Unspecific binding sites were blocked by incubation with $5 \%$ BSA in PBS-T for 3 hours, followed by incubation with primary antibody (anti-VAChT) 1:500 (2.5\% BSA in PBS-T 1\%) for 30 minutes at room temperature. Muscles were stored at $4{ }^{\circ} \mathrm{C}$ over night. The next day they were incubated at room temperature for $30 \mathrm{~min}$; they were washed using $0.05 \%$ Triton in PBS, then incubated with the secondary antibody (goat anti-rabbit Alexa 488 diluted 1:500) and the postsynaptic dye $(1.25 \mu \mathrm{l} / \mathrm{ml}$ BTX Alexa Fluor 647$)$ in $5 \%$ BSA in PBS-T 0.05\%. After washing with PBS-T $0,05 \%$ the muscles were finally mounted under the stereoscopic microscope with slowfade medium.

\section{Synaptic Vesicles staining with SV2 and AChT labeling}

The muscles were dissected in hepes solution (see section solutions and buffers). Subsequently fixed in $4 \%$ paraformaldehyde and washed with PBS, followed by 30 min incubation with glycine $0,1 \mathrm{M}$ in PBS at room temperature and permeabilization with $1 \%$ Triton X-100 in PBS. Unspecific binding sites were blocked by incubation with $5 \%$ BSA in PBS-T for 2 hours at room temperature and then at $4{ }^{\circ} \mathrm{C}$ over night. After incubation at room temperature for $30 \mathrm{~min}$, the preparations were incubated with primary antibodies (anti-SV2) and (anti- VAChT) 1: 500 (2.5\% BSA in PBS-T 1\%) for 2 hours at room temperature, followed by washing with PBS-T $1 \%$. Together with the postsynaptic dye (1 $\mu \mathrm{l} / \mathrm{ml}$ BTX Rhodamine), they were incubated for 1 hour with secondary antibodies goat anti-rabbit Alexa 488 and goat anti-mouse Alexa 647 1:500 diluted in 5\% BSA in PBS-T $0.05 \%$. Before mounting the preparation under the stereoscopic microscope they were washed with PBS-T 0, $05 \%$.

\section{Synaptic Vesicles and Actin staining}

The muscles were dissected in Hepes solution (see section 2.3.4.3. solutions and buffers) and then fixed in $4 \%$ paraformaldehyde, washed with PBS and set at $4{ }^{\circ} \mathrm{C}$ over night. Subsequently they were incubated with glycine $0,1 \mathrm{M}$ in PBS at room temperature, then permeabilized with $1 \%$ Triton X-100 in PBS. Unspecific binding sites were blocked by incubation with 5\% BSA in PBS-T for 3 hours. Followed by incubation with primary antibody (anti-VAChT) 1:500 (2,5\% BSA in PBS-T 1\%) for 30 minutes at room temperature. They were stored at $4{ }^{\circ} \mathrm{C}$ over night. The next day they were incubated at room temperature for $30 \mathrm{~min}$; they were washed using $0.05 \%$ Triton in PBS, then incubated with 
the secondary antibody (goat anti-rabbit Alexa 488 diluted 1:500), the actin dye $(25 \mu \mathrm{l} / \mathrm{ml}$ Alexa fluors 647 phalloidin) and the postsynaptic dye $(1.25 \mu \mathrm{l} / \mathrm{ml}$ BTX-Rhodamine red) in $5 \%$ BSA in PBS-T 0,05 \%. After washing with PBS-T 0,05\% the muscles were finally mounted under the stereoscopic microscope with slowfade medium.

\subsubsection{Confocal Microscopy}

Muscles were imaged with an upright Olympus FV1000 confocal laser scanning microscope, equipped with three excitation laser lines (488, 561 and $633 \mathrm{~nm})$. A 10x objective was used for coarse localization of nerve terminals within the preparation. Images were taken using a $63 x$ oil-immersion objective with a numerical aperture of 1.4. Fluorescence emission was detected sequentially by selecting the appropriate filter settings, as given in the Table 4 .

\begin{tabular}{|l|r|r|}
\hline Label & Exc Max (nm) & Em Max nm \\
\hline$\alpha$-Bungarotoxin Alexa Fluor 647 & 650 & 668 \\
$\alpha$-Bungarotoxin Rhodamine & 552 & 579 \\
Secondary Antibody Alexa488 & 495 & 519 \\
Alexa flour 647 phalloidin & 650 & 668 \\
Mito Tracker Orange CMX Ros & 554 & 576 \\
\hline
\end{tabular}

Table 4: Filter settings for detection of specific fluorescent labels.

\subsubsection{Image Analysis with ImageJ}

Transferring the image from the Olympus Fluoview program to the Image $\mathbf{J}$ program

The Olympus Fluoviewprogram was used to acquire the emission of each dye, for example BTX far red, Mito Tracker and Alexa Flour 488 in individual channels in three (X-Y-Z) dimensions. The $\mathrm{Z}$ dimension was represented as a series of slices, showing the emission from different depth levels at intervals of $0.5 \mu \mathrm{m}$. The images were imported from the Olympus Fluoview program to the Image $\mathrm{J}$ program in a RGB red green and blue color format as a sequence containing images at about 8 z-positions per fluorescence channel. The image sequence from different depth levels of each channel was transformed to a Z-projection, when required. After setting the scale in $\mu \mathrm{m}$ corresponding to one pixel, Z-projections were used for imaging analysis. In some cases single slices were used for analysis, if mentioned in the text.

\section{Measuring the postsynaptic area}

The Z-projection showing the postsynaptic area labeled by BTX -Rhodamine or BTX-Far red, was converted from RGB color image to an 8 bit grayscale image. The image was segmented into regions of interest and background by setting interactively lower and upper 
threshold values. The area of a selected region was then measured in square micrometers using image $\mathrm{J}$ routines.

\section{Measuring the area of synaptic vesicle clusters}

In order to measure the synaptic vesicle clusters, lower and upper threshold values were set as for the postsynaptic side, with the difference that the areas of interest were analyzed in "particles analyzing mode" by manually setting the threshold until edges of each vesicle cluster were defined. Then the individual areas of each cluster were measured.

\section{Measuring the area of the mitochondria clusters}

In contrast to synaptic vesicles, mitochondria are present in all cells. To measure only the mitochondria inside the terminal we used the postsynaptic area as a mask and cleared all signals outside this region. The mitochondria inside the synaptic terminal were then measured in "particles analyzing mode", similar to the analysis of vesicle clusters.

\section{Actin measurements}

In transverse single confocal slices the diameters of F-actin rings surrounding SVs could be estimated from their respective line-intensity profiles. From maximum projected confocal images actin areas were determined automatically, by defining masks based on brightness thresholding. To measure only the actin inside the terminal we used the postsynaptic area as a mask and cleared outside signals before measuring actin.

\section{Quantification of the nearest-neighbor distances between SV clusters and mi- tochondria spots}

Nearest-neighbor distances between mitochondria and SV clusters were determined by fitting each of the red and green spots to a 2D gaussian distribution, and using the distances between the peaks $(\mathrm{x}, \mathrm{y})$ of the distributions.

\subsubsection{Statistics}

Unless otherwise stated all values indicate mean \pm standard error of the mean (sem) and numbers $(n)$ refer to the number of terminals. Differences between groups were tested using the $t$-test ( 2 tailed). 


\section{Chapter 3}

\section{Results}

The results of this work have been incorporate into our publication "SMN Requirement for Synaptic Vesicle, Active Zone and Microtubule Postnatatal Organisation in Motor Nerve Terminals" (Torres-Benito et al 2011).

\subsection{Synaptic Vesicles}

\subsubsection{Deficits in Synaptic Vesicle Maturation}

Synaptic Vesicles (SV) together with mitochondria are the main organelles in the nerve terminal. A disturbed distribution or reduced amount of SVs could provide an explanation for the observed $55 \%$ decrease of evoked neurotransmitter release in TVA muscle of SMA mice (Ruiz et al 2010).

We used an antibody against the vesicular ACh transporter (VAChT) in combination with a secondary antibody, conjugated with a green fluorophore to explore the SVs spatial organization. In particular the total area of the terminal covered by SVs was determined. To better localize the NMJ we labeled, like in all the following experiments, also the postsynaptic side with $\alpha$-Bungarotoxin ( $\alpha$-BTX), which binds to the nicotinic acetylcholine receptor $(\mathrm{nAChR})$, in this case conjugated with rhodamine.

Spinal Muscular Atrophy progresses during development. To get insight into the presynaptic maturation process, we examined synaptic structures in mice at postnatal day seven (P7) and 14 (P14). We used TVA muscle, one of the most affected ones in this disease (Murray et al 2008) (Ruiz et al 2010).

The confocal images show that SVs are organized in clusters (Fig. 11 for P7 and Fig. 12 for P14). In wild-type (WT) mice, at the beginning of the NMJ postnatal maturation period (first week of life), SV clusters were observed to be small (Fig. 11A), but by the second week, as WT NMJs matured, SVs covered larger areas of the terminal (Fig. 12A). In SMN deficient terminals, however, SV clusters remained small (compare Fig. 12A, upper and lower panels).

Also, at the postsynaptic side, images taken at P14 showed signs of immaturity. 

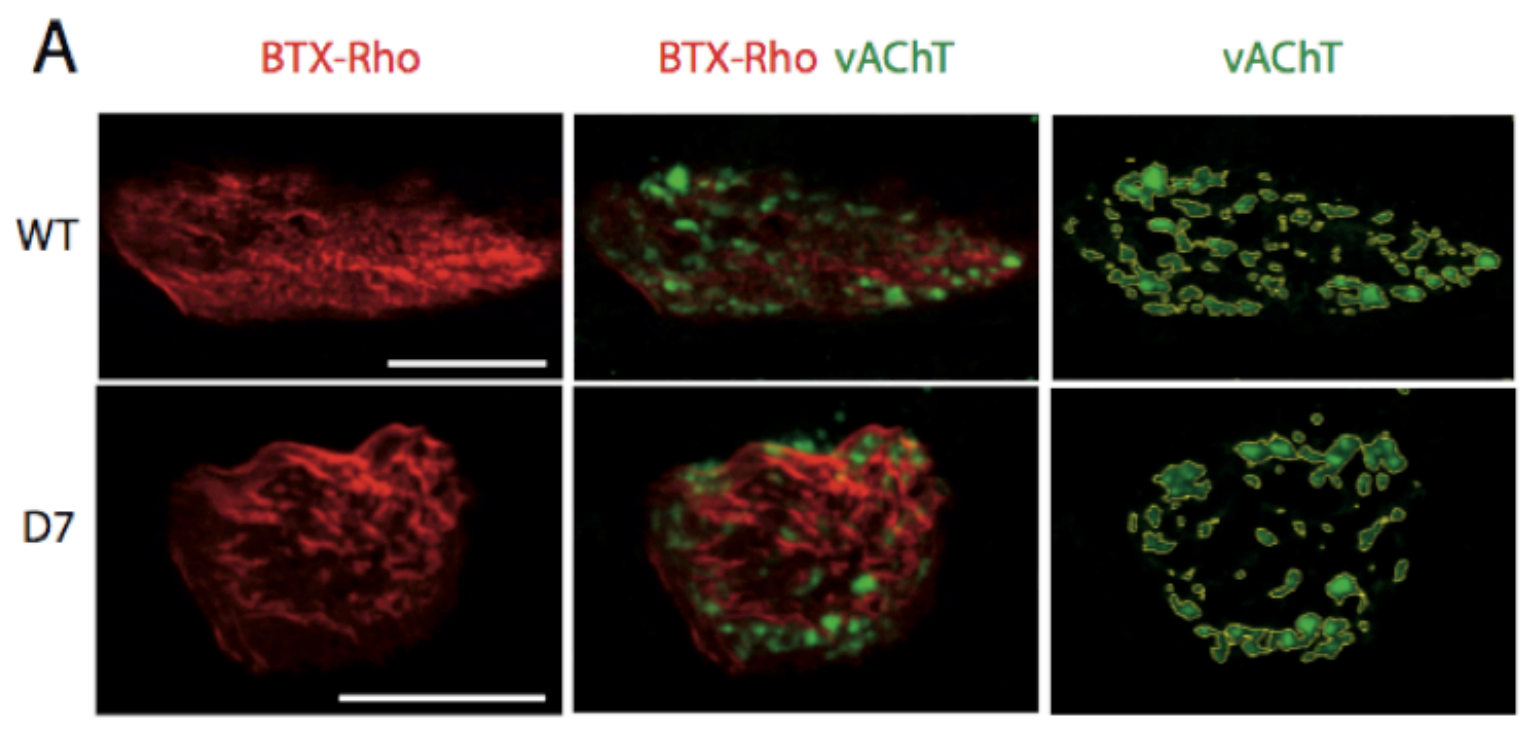

B

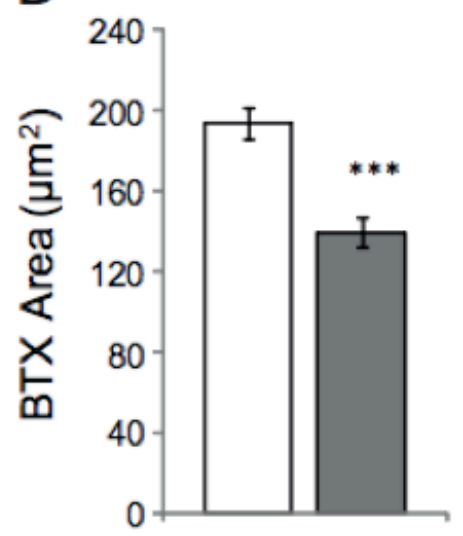

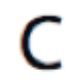

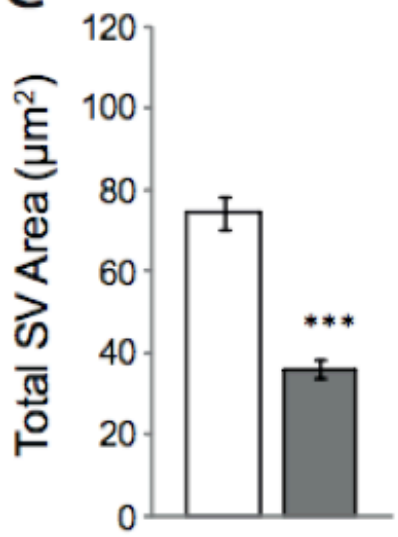

D

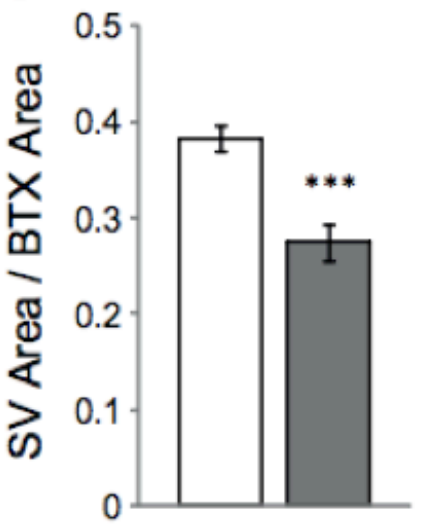

Figure 11: Representative en face views of NMJs from the TVA muscle at P7 stained with BTX-Rho (red), which binds specifically to postsynaptic AChRs, and antiVAChT (green), which labels synaptic vesicles. Images are Z-stack projections. A. Terminals of WT (upper panels) and SMN $\Delta 7$ mice (lower panels) respectively, at P7. Panels B; C \& D show mean values ( \pm sem) of BTX area, total synaptic vesicle area and their ratio respectively both for WT (white bars) and mutants (grey, filled bars). Scale bars: $10 \mu \mathrm{m}^{*}: P<0.05$; ${ }^{* *}: P<0.005$; $* * *: P<0.0005$. 

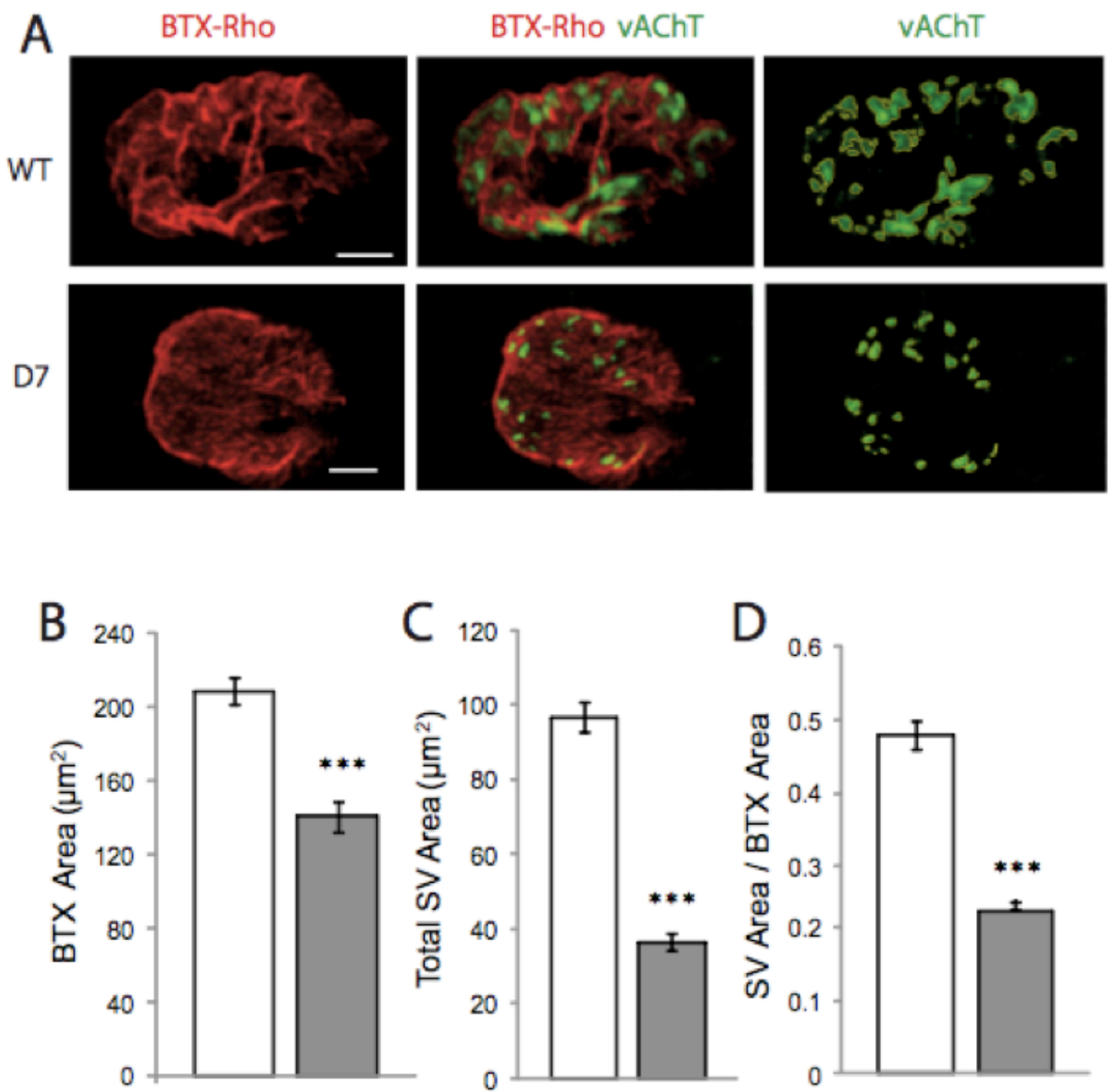

Figure 12: Representative en face views of NMJs from the TVA muscle at P14 stained with BTX-Rho (red), which binds specifically to postsynaptic AChRs, and antiVAChT (green), which labels synaptic vesicles. A. Terminals of WT (upper panels) and SMN $\Delta 7$ mice (lower panels) respectively, at P14. Note the signs of immaturity in the SMN $\Delta 7$ terminals: no clear folders or perforations at the postsynaptic side in SMN $\Delta 7$ (left, lower panel) compared to WT (left, upper panel). SVs at the presynaptic terminal remain small in SMN $\Delta 7$ mice (right, lower panel). B. Mean postsynaptic area in SMN $\Delta 7$ (grey, filled bars) and in WT terminals (white bars) are significantly different. C. The total area of vesicles stained with VAChT is smaller in $\Delta 7$ mice than in WT motor terminals. $\mathbf{D}$. The relative area covered by vesicles in relation to the area covered by postsynaptic receptors is less than half in SMN $\Delta 7$ terminals. Scale bars: $10 \mu \mathrm{m}$ ${ }^{*}: P<0.05 ;{ }^{* *}: P<0.005 ;{ }^{* * *}: P<0.0005$. 
While in control littermates band structures were apparent, representing BTX, which resides at the lips of infoldings, no such features were obvious in images from mutants (compare Fig. 12A upper and lower panels). A quantitative analysis of the images is shown in Figure 11B-D and 12B-D.

Measuring the area of the postsynaptic side (see methods) showed that NMJs are smaller in mutants both at P7 and P14 (Fig. 11B \& 12B, respectively). Therefore, the areas covered by SVs were normalized to those of the postsynaptic terminal, in order to compare the fractional area covered by SVs between mutants and control. The total surface of the terminal covered by SVs was $\sim 30 \%$ smaller in SMN deficient terminals (n $=37$ NMJs from 3 mice) than in WTs $(\mathrm{n}=38$ NMJs from 3 mice) already at P7 (Fig. $11 \mathrm{C} \& \mathrm{D} P<0.0001$ ). At P14, this difference became even larger, near 50\%, (Fig. 12C $\& \mathrm{D} ; P<0.0001 ; \mathrm{WT}: \mathrm{n}=52 ; \Delta 7: \mathrm{n}=58$ terminals). In addition, the size of SV clusters was smaller in mutants than in WTs, both at $\mathrm{P} 7(\sim 30 \%$; $\mathrm{P}=0.02)$ and, much more so, at P14 (75\%; $P<0.0001)$. This analysis shows the phenomena of maturation in a remarkable way: in littermate controls the clusters size increased and the number of clusters diminished (see Table 5) from P7 to P14. In contrast, in mutants this process was not observed, no change in cluster size, nor in the number of clusters per terminal took place during the second week of life. 


\subsubsection{VAChT and SV2 colocalize in SMA Motor Terminals}

To test whether the clustering of SVs observed in the TVA muscle of SMA mutants with anti-VAChT antibodies could also be seen with another vesicle marker, a double staining of SVs using antibodies against VAChT, and the synaptic vesicle protein 2 (SV2) was performed. The vesicular fluorescence patterns observed with anti-VAChT (red) were also seen with anti-SV2 (green), both in WT (Fig. 13A), and in mutant terminals (Fig. 13B). Quantitative analysis of the immunofluorescence signals indicated that the colocalization indexes (see Methods) of these two markers were $\sim 0.9$ in both types of mice. These data corroborate the smaller size of the clusters in SMA mutant terminals, and rule out the existence of an atypical vesicle population devoid of the vesicular transporter.
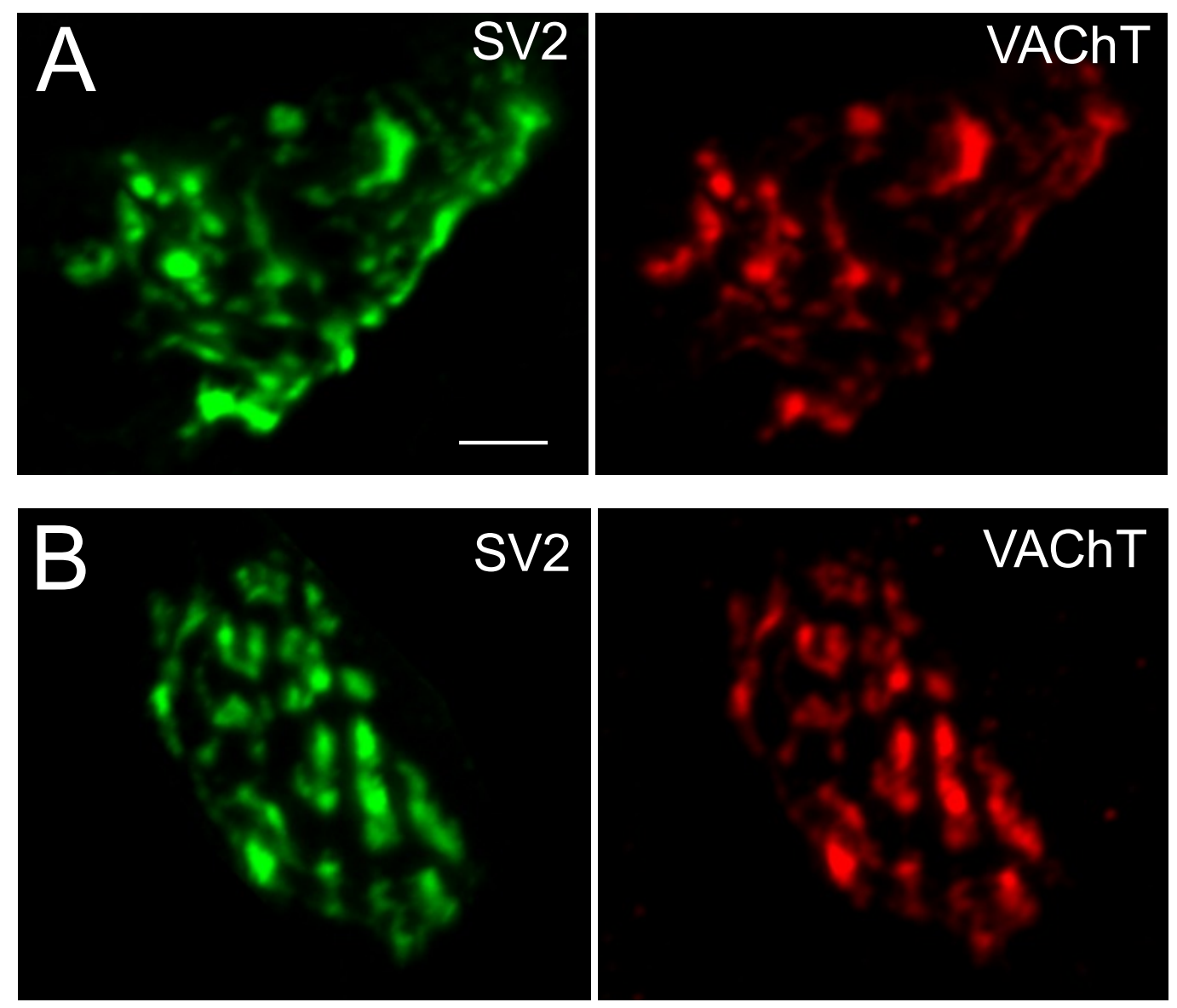

Figure 13: VAChT and SV2 colocalize in SMA synaptic vesicles. A \& B. Examples of WT and SMA $\Delta 7$ terminals at P14 from TVA muscles. Images are Z-stack projections. Scale bar: 5 $\mu \mathrm{m}$. 


\subsubsection{A reduced SV pool can coexist with a mature Postsynaptic Terminal in LAL Muscle.}

The data presented above show that SMA deficiency produces pre- and postsynaptic defects in the TVA muscle, and raise the question of how much the pre- and the postsynaptic phenotypes are interrelated in SMN deficient mice. Therefore, it was explored whether the vesicle content was also anomalous in the LAL muscle of SMA mutants, a muscle, in which postsynaptic terminals have been described to mature almost at the same pace as in control mice Murray et al (2008). The analysis, as described for the TVA, therefore, was repeated in the LAL.

Because previous work has identified a selective vulnerability of the nerve terminals in the caudal band in comparison to the rostral band of the LAL muscle (Murray et al., 2008; Ruiz et al., 2010), the size of the postsynaptic side and the organization of SVs at NMJs in both bands was compared.

In the rostral band there was no significant difference in the size of the postsynaptic side at P7 (Table 5), and P14 (Fig. 14 E and Table 5). Also in the caudal band there was no difference in size of the postsynaptic side at P7 (Table 5). Only in the caudal band at P14 the size of the postsynaptic side was $\sim 23 \%$ reduced in mutants (Fig. 14B). In comparison: in TVA muscle at P14 the size of the postsynaptic side was $\sim 33 \%$ smaller in mutant relative to $\mathrm{WT}$.

At P7 in the rostral band, SV area and mean cluster area (Table 5) were not different in WTs $(\mathrm{n}=21$ terminals $)$ and mutants $(\mathrm{n}=22$ terminals $)$, while both parameters were significantly reduced in mutants at P14 (Table 5). More specifically, at P14 the mean SV area was reduced $\sim 52 \%$ and mean size of SVs clusters was reduced $\sim 66 \%$ in mutant (Fig. $14 \mathrm{~F} \& \mathrm{G}),(\mathrm{P}=0.0003$ and $\mathrm{P}=0.006$, respectively). In the caudal part, however, both parameters were already decreased at P7 in mutants. At P7 the SV area was $\sim 49 \%$ and the SV cluster size was $\sim 57 \%$ smaller (Table 5). At P14 this difference even increased, the $\mathrm{SV}$ area was $\sim 73 \%$ and the SVs cluster size $\sim 83 \%$ reduced (Fig.14C \& D, respectively).

These results demonstrate that the observed abnormalities are not a property of the TVA muscle alone. Moreover, they confirm the selective vulnerability of the caudal band of the LAL muscle. The finding that the maturation of the postsynaptic end-plates takes place normally while there are early presynaptic defects, shows that pre- and postsynaptic defects can occur independently from each other. 
A

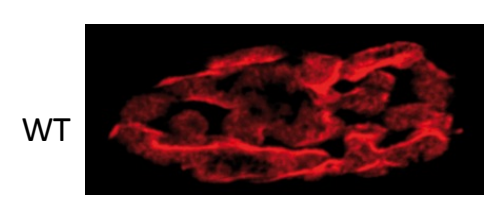

D7
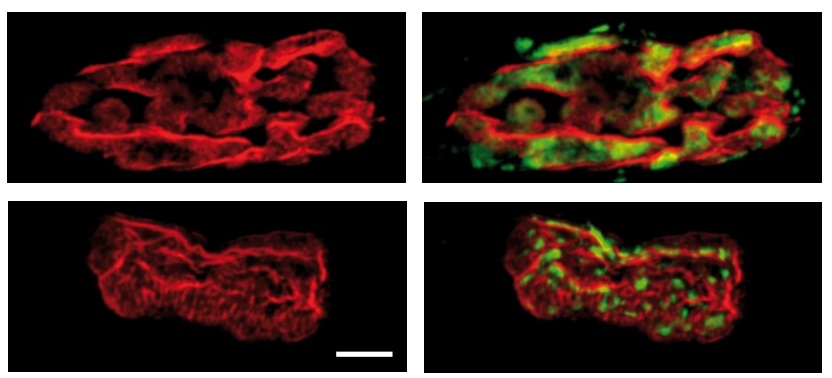

\section{caudal}

B

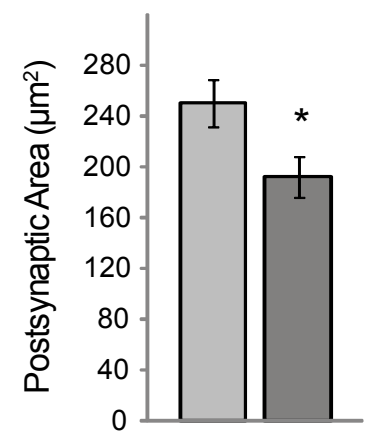

E

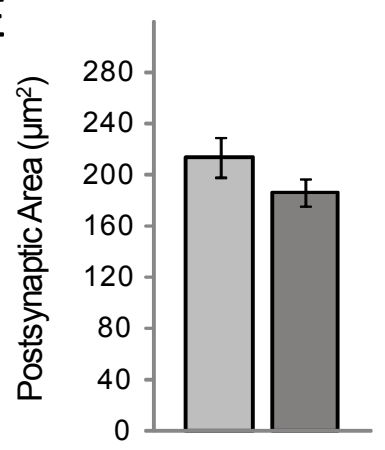

C

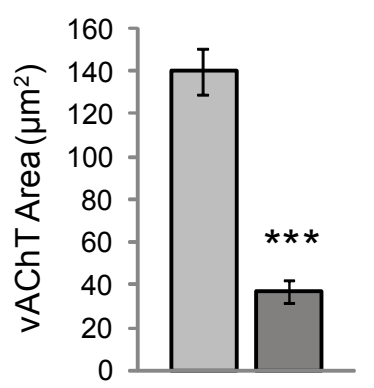

$\mathrm{F}$

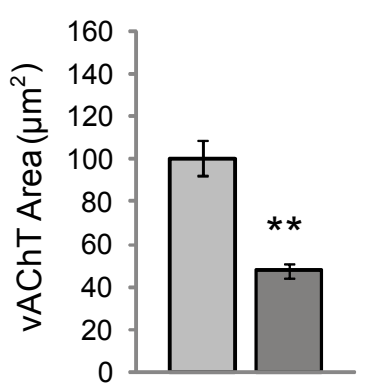

vAChT
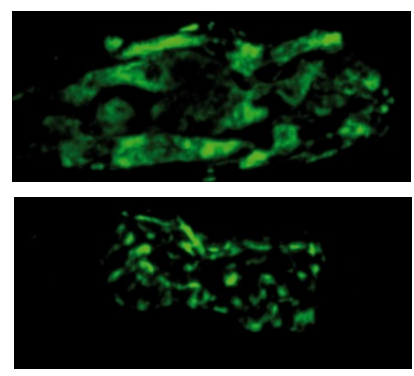

D

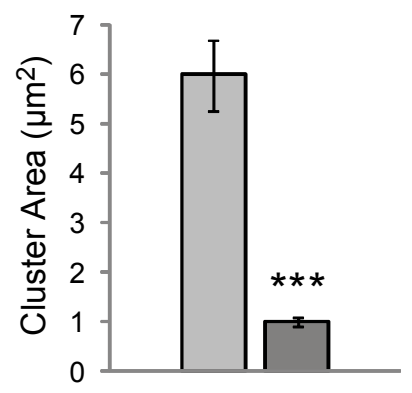

G

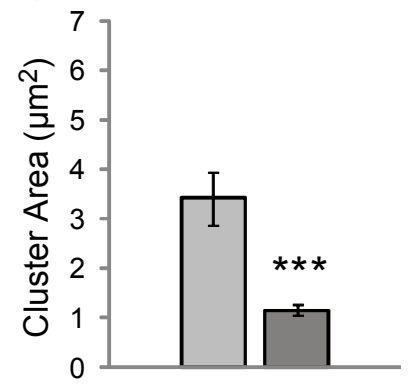

Figure 14: Synaptic vesicle reduction and anomalous distribution in SMA motor terminals from LAL muscles despite mature postsynaptic side. A \& B. Representative images of pre- and postsynaptic characteristics of NMJs in the LAL muscles of WT (upper panels) and SMN $\Delta 7$ (lower panels) mice at P14. Postsynaptic terminals were labeled with BTX-Rho (red) and presynaptic vesicles with antibodies against VAChT (green). Note the clustering of SVs despite the mature appearance of the postsynaptic side in the $\operatorname{SMN} \Delta 7$ terminal. Scale bar: $5 \mu \mathrm{m}$. B-G. Mean postsynaptic area $(B \& E), S V$ area $(C, F)$, and cluster area $(D, G)$ in SMN $\Delta 7$ and $W T$ terminals, from rostral (B-D) and caudal (E-G) divisions of the muscle at P14. Note that the area of vesicles and the cluster sizes were significantly reduced at P14. However, in the caudal part SV deficiencies in SMN $\Delta 7$ terminals were evident since P7 ( $\mathrm{n}=16$ WT terminals and $\mathrm{n}=15$ SMN $\Delta 7$ terminals). Scale bars: $10 \mu \mathrm{m} *: P<0.05$; ${ }^{* *}: P<0.005$; ***:P<0.0005 (modified from our publication Torres-Benito L, Neher MF, Cano R, Ruiz R, Tabares L. 2011). 


\begin{tabular}{|c|c|c|c|c|c|c|c|c|c|}
\hline & \multicolumn{2}{|c|}{$\begin{array}{l}\text { BTX Area } \\
\left(\mu m^{2}\right)\end{array}$} & \multicolumn{2}{|c|}{$\frac{\text { SV Area }}{\text { BTX Area }}$} & \multicolumn{2}{|c|}{$\begin{array}{l}\text { SV Cluster } \\
\text { size }\left(\mu m^{2}\right)\end{array}$} & \multicolumn{2}{|c|}{$\frac{\text { Number Cluster }}{\text { BTX Area }}$} \\
\hline & & $\bar{~} \mathrm{WT}$ & $\overline{\mathrm{D} 7}$ & $\overline{\mathrm{WT}}$ & $\overline{\mathrm{D} 7}$ & "WT & 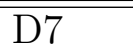 & WT & $\overline{\mathrm{D} 7}$ \\
\hline \multicolumn{10}{|l|}{ TVA } \\
\hline \multirow{3}{*}{ P7 } & Mean & 193,3 & 139,2 & 0,383 & 0,274 & 2,304 & 1,628 & 0,192 & 0,201 \\
\hline & sem & 7,548 & 7,475 & 0,0133 & 0,0185 & 0,207 & 0,212 & 0,01 & 0,011 \\
\hline & $\mathrm{n}$ & 38 & 37 & 38 & 37 & 38 & 37 & 38 & 37 \\
\hline \multirow{3}{*}{ P14 } & Mean & 208,3 & 140,2 & 0,479 & 0,239 & 6,687 & 1,772 & 0,09697 & 0,19145 \\
\hline & sem & 8,338 & 6,77 & 0,019 & 0,014 & 0,632 & 0,1598 & 0,0055 & 0,009 \\
\hline & $\mathrm{n}$ & 52 & 58 & 52 & 58 & 65 & 68 & 52 & 58 \\
\hline LAL & Rostral & & & & & & & & \\
\hline \multirow{3}{*}{$\mathrm{P} 7$} & Mean & 185,2 & 181,1 & 0,28 & 0,2684 & 1,627 & 1,375 & & \\
\hline & sem & 11,452 & 13,678 & 0,0262 & 0,023 & 0,311 & 0,2045 & & \\
\hline & $\mathrm{n}$ & 21 & 22 & 21 & 22 & 21 & 22 & & \\
\hline \multirow{3}{*}{ P14 } & Mean & 213,7 & 186,1 & 0,47016 & 0,2612 & 3,411 & 1,1525 & & \\
\hline & sem & 15,7863 & 11,037 & 0,02615 & 0,0176 & 0,55 & 0,105 & & \\
\hline & $\mathrm{n}$ & 7 & 12 & 7 & 12 & 7 & 12 & & \\
\hline LAL & Caudal & & & & & & & & \\
\hline \multirow{3}{*}{ P7 } & Mean & 173,2 & 168,4 & 0,367 & 0,193 & 2,0975 & 0,9 & & \\
\hline & sem & 9,391 & 12,058 & 0,0396 & 0,019 & 0,338 & 0,1 & & \\
\hline & $\mathrm{n}$ & 16 & 14 & 16 & 14 & 16 & 14 & & \\
\hline \multirow{3}{*}{ P14 } & Mean & 250,1 & 191,8 & 0,574 & 0,197 & 5,9863 & 0,999 & & \\
\hline & sem & 18,5996 & 16,05 & 0,0393 & 0,024 & 0,717 & 0,0861 & & \\
\hline & $\mathrm{n}$ & 11 & 15 & 11 & 15 & 11 & 15 & & \\
\hline
\end{tabular}

Table 5: Summary of synaptic vesicle and postsynaptic side properties in TVA and LAL muscle. Comparison between WT (wild type) and D7 (SMA mutant) in TVA (Transversus Abdomnis Muscle) and LAL (Levator Auris Longus muscle) at P7 (seven days old mice) and P14 (fourteen days old mice), regarding BTX Area $\left(\mu m^{2}\right)$ (area of postsynaptic side), SV Area/BTX Area (Area of the synaptic vesicles divided by area of postsynaptic side), SV cluster size $\left(\mu m^{2}\right)$ (mean size of one single vesicle synaptic vesicle cluster) and number of clusters/BTX Area. Data in mean, sem (standard error of the mean) and $n$ (number of observations).

\subsection{Mitochondria}

\subsubsection{Mitochondria Clusters are smaller in SMA Motor Termi- nals}

Mitochondria provide ATP for synaptic transmission, ion pumps, and the assembly of the actin cytoskeleton involved in the clustering of SVs and mitochondria themselves (Hirokawa and Takeda 1998; Langford 2002). Furthermore they regulate intraterminal $\mathrm{Ca}^{2+}$ levels, providing an especially important buffering action during trains of action potentials David 


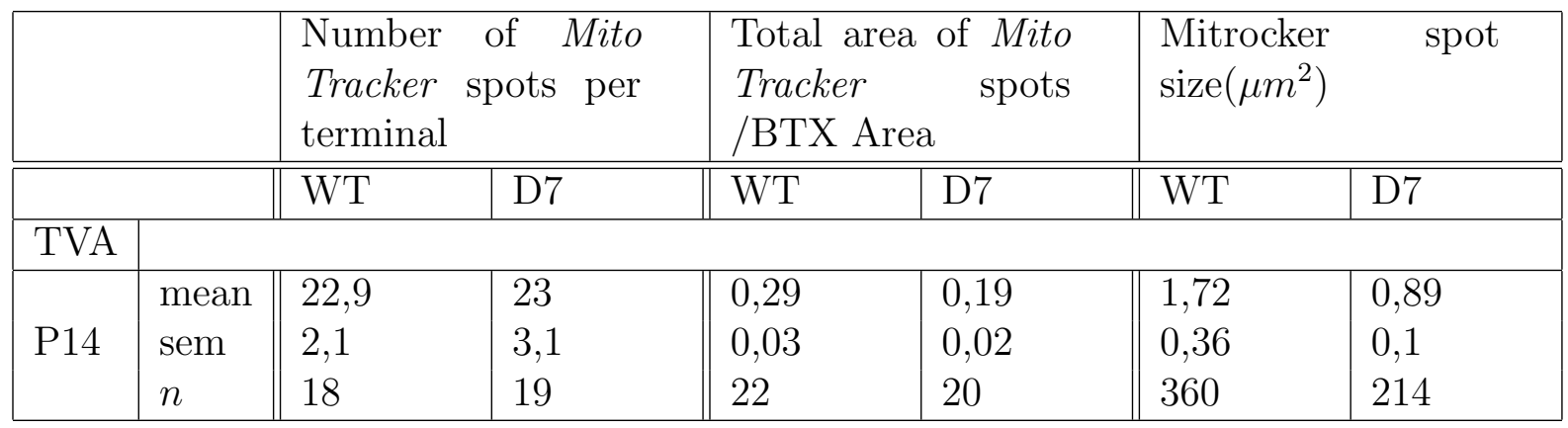

Table 6: Summary of mitochondria properties in TVA muscle. Comparison between WT (wild type) and D7 (SMA mutant) in TVA (Transversus Abdominus Muscle) at P14 (fourteen days old mice), regarding Number of Mito Tracker spots per terminal. Total area of Mito Tracker Spots /BTX Area $\left(\mu m^{2}\right)$ and Mito Tracker spot size $\left(\mu m^{2}\right)$. Data in mean, sem (standard error of the mean) and $n$ (number of observations).

and Barrett 2000). Therefore, a reduction in the number of mitochondria, alterations in their spatial distribution, or impairment of their functional capacities may decrease their $\mathrm{Ca}^{2+}$ buffering capability and produce toxic $\mathrm{Ca}^{2+}$ overloads. To assess whether the spatial distribution of mitochondria or their density was altered in SMN deficient terminals, the TVA muscle was incubated with Mito Tracker (400 nM), a cell-permeant probe that is sequestered by intact mitochondria and retained during cell fixation (Poot et al 1996).

Figure 16 A-D (central panels) shows representative examples of the distribution of Mito Tracker labeled mitochondria in motor terminals at P14. The total area stained by Mito Tracker per terminal was about half in mutants $(19.4 \pm 2.7 \mu \mathrm{m} 2 ; \mathrm{n}=20)$ as compared to WT terminals $(38.8 \pm 4.9 \mu \mathrm{m} 2 ; \mathrm{n}=22 ; \mathrm{P}=0.002)$. Normalization of these areas to postsynaptic surfaces also gave significantly smaller values in mutants (WT: 0.29 \pm 0.03 ; mutant: $0.19 \pm 0.02 ; \mathrm{P}=0.01$ ) (Figure 15A). This difference was mainly due to the smaller size of the Mito Tracker spots (WT: $1.72 \pm 0.36 \mu \mathrm{m} 2, \mathrm{n}=360$ spots; mutant: $0.89 \pm 0.1 \mu \mathrm{m} 2, \mathrm{n}=214$ spots. $P=0.03$ ) in mutants (Figure $15 \mathrm{C}$ ). Quantification of the number of Mito Tracker microregions per terminal showed no significant differences between WT and mutants (WT: $22.9 \pm 2.1$ spots/terminal, $\mathrm{n}=18$ terminals; mutant 23.5 $\pm 3.1, \mathrm{n}=19$ terminals $)(P=0.9)$ (Figure $15 \mathrm{C})$.

These properties of mitochondria in TVA muscle of SMA mice compared to wild type are also shown in Table 6.

\subsubsection{Co-clustering of Mitochondria and SV clusters}

Next, we explored the spatial relationship between Mito Tracker spots and SV clusters. In most cases, as in the illustrated examples, mitochondria (red) appeared near SV clusters (green) in both WT (Fig. 16A \& B) and mutant terminals (Fig. 16C \& D). Moreover, in many cases a core of mitochondria was clearly surrounded by a SV rim (Fig. 16A-D, right panels), reminiscent of the donut-like structures described in the calyx of Held, Wimmer et al (2006) and Perkins et al (2010). 


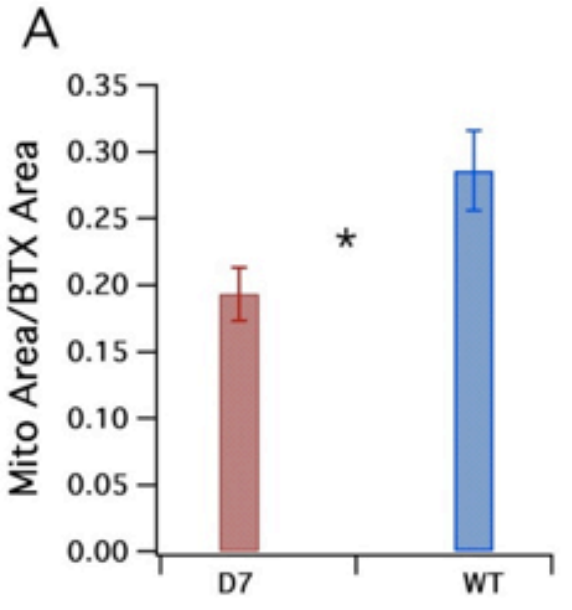

B

C

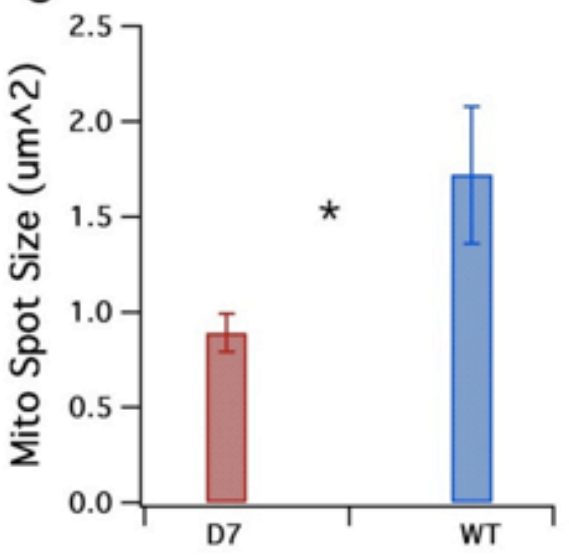

D

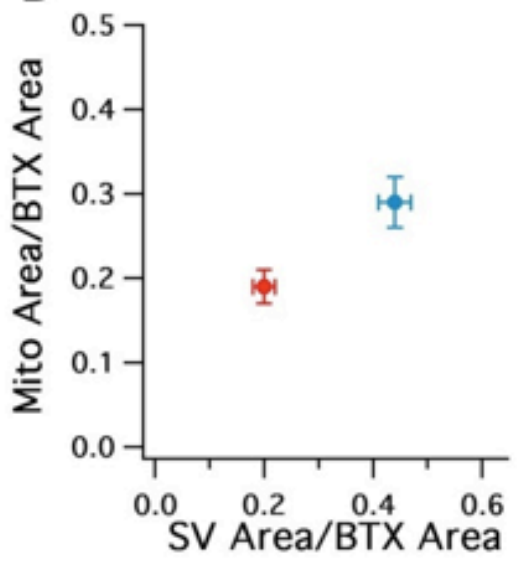

Figure 15: A-D. Staining of mitochondria with Mito Tracker in WT (wild type) and D7 (mutant mice) in TVA muscle at P14. A. The total area stained by Mito Tracker normalized to the postsynaptic surfaces was significantly reduced in mutant. B. Quantification of numbers of Mito Tracker spots per terminal showed no significant difference between WT and mutant. C. The size of Mito Tracker spots is smaller in mutant. D. Relationship between mean areas covered by SV and mitochondria in WT (blue) and SMA $\Delta 7$ (red) terminals. ${ }^{*}: P<0.05$. 
To quantify this observation we measured the nearest-neighbor distances between SV clusters and mitochondria spots. Nearest-neighbor distances were determined by fitting each of the red and green spots to a 2D Gaussian distribution, and using the peak (x,y) of each distribution. The results in nine mutant terminals (202 measurements) and 13 WT terminals (282 measurements), showed that in mutants SV and mitochondria were closely associated, as in controls (Fig. 16 E). Even more, the percent of red-green spots nearest distances within $1 \mu \mathrm{m}$ were larger in mutants $(41 \%)$ than in WT $(31 \%)(\mathrm{P}=0.0006)$, as expected for the smaller sizes of SV and mitochondria cluster in mutants. Taken together, these results show that in nerve terminals mitochondria and SVs clusters are localized in pairs. This aspect of the spatial organization is not altered in mutant terminals, whereas the fractional area covered by mitochondria is reduced.

\section{$3.3 \quad$ F-actin}

\subsubsection{F-actin forms ring-like Structures around SV Clusters}

Filamentous actin (F-actin) is a prominent cytoskeletal element in nerve terminals. The F-actin-based network may participate in creating a scaffold for SV clustering, and/or in supporting ordered vesicle mobility (Hirokawa et al 1989). In addition, it has been suggested that F-actin anchors synaptic vesicles to AZs by a labile link formed with synapsin, a vesicle protein De Camilli et al (1990) and Greengard et al (1993).

SMN deficiency produces defects in $\beta$-actin mRNA axonal transport, and a decrease in actin protein content in growth cones of motoneurons in culture (Rossoll et al 2003). We explored F-actin content and distribution in presynaptic TVA motor terminals of SMA mutant mice. F-actin was revealed by binding to fluorescent Phalloidin-Alexa 647, which binds to all isoforms of F-actin but not to monomeric actin (Wulf et al 1979). In addition, to gain insight into the role of $\mathrm{F}$-actin in the organization of SV, the distributions of $\mathrm{F}$-actin relative to SV were also examined.

F-actin was localized in the sub-plasmalemmal region, extending into the cytoplasm and forming a thin network. Figure 17A shows a WT terminal with F-actin labeled with phalloidin (upper panel), SV labeled with VAChT antibodies (green), and postsynaptic receptors labeled with BTX-Rho (red, lower panel). In Figure 17B a typical terminal from a mutant mouse is shown (left panel, phalloidin image; central panel, anti-VAChT and BTX-Rho merged). In some cases, F-actin was also clearly visualized in the axon (Fig. 17B, arrow in right panel). In WT and mutant mice, F-actin filaments run parallel to the major axis of the terminal and SV clusters are positioned along them.

The association between SV clusters and actin could be better visualized in transverse single confocal slices. Figure 17C (WT) and 17D (mutant) present two representative examples showing SV clusters surrounded by F-actin, forming ring-like structures, similar to actin rings described in the lamprey reticulospinal giant synapse (Shupliakov et al 2002). Interestingly, the diameter of F-actin rings surrounding SV were apparently smaller in mutant than in WT terminals, as could be appreciated by their respective line intensity 

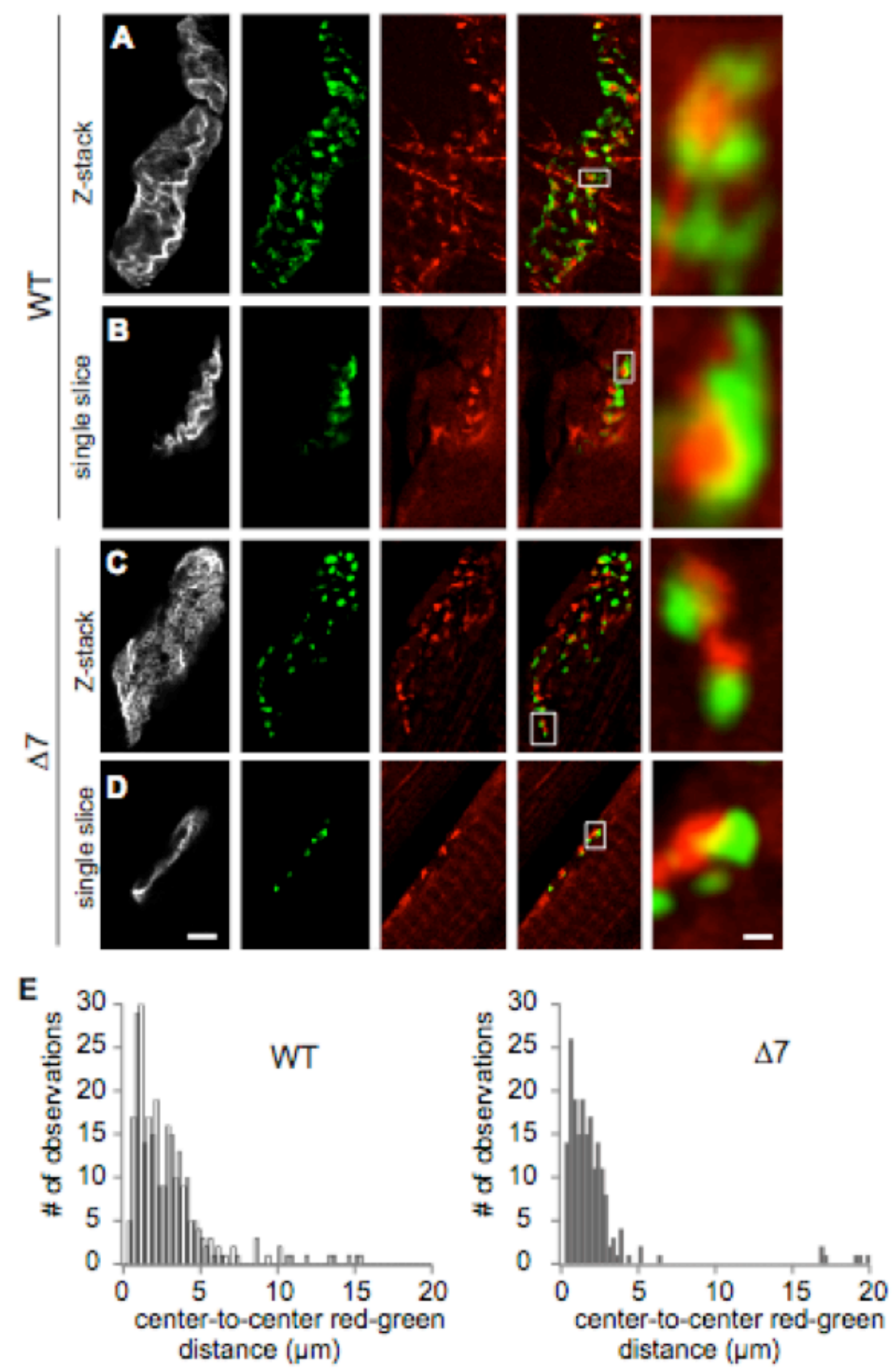

Figure 16: Mitochondrial density in SMA presynaptic terminals is reduced. Data are from the TVA muscle (P14).A - D. The upper panels (A \& C) show Z-stack projections while the lower panels (B \& D) show single confocal sections. The staining from left to right are: BTX-A647 (grey), SVs (green), Mito Tracker (red), merge of SV and mitochondria. E. Nearest neighbor distributions of SV clusters and mitochondrial regions (calculated from their respective center of mass), in WT and mutants terminals. Scale bars A-D: $5 \mu \mathrm{m}$; insets: $600 \mathrm{~nm}$ (from our publication Torres-Benito $\mathrm{L}$, Neher MF, Cano R, Ruiz R, Tabares L., 2011) 
profiles across SVs and phalloidin loops (Fig. 17E). However, these structures were not visualized frequently enough for statistical analysis. Thus, the percentage of the terminal area covered by phalloidin, normalized to the postsynaptic area, was quantified (Fig. 17F). In WT mice, although the area of the terminal covered by phalloidin was apparently larger than in mutants (WT: $41 \pm 9 \%, \mathrm{n}=6$ terminals; mutants: $34 \pm 4 \%, \mathrm{n}=6$ terminals), this difference did not reached statistical significance $(\mathrm{P}=0.5)$.

Taken together, these results show that, although a slight reduction of the F-actin based network is difficult to quantify, F-actin is still present in high amounts in the mutant and, similarly to the wild type case, closely associated with SVs in the form of ring-like structures. 

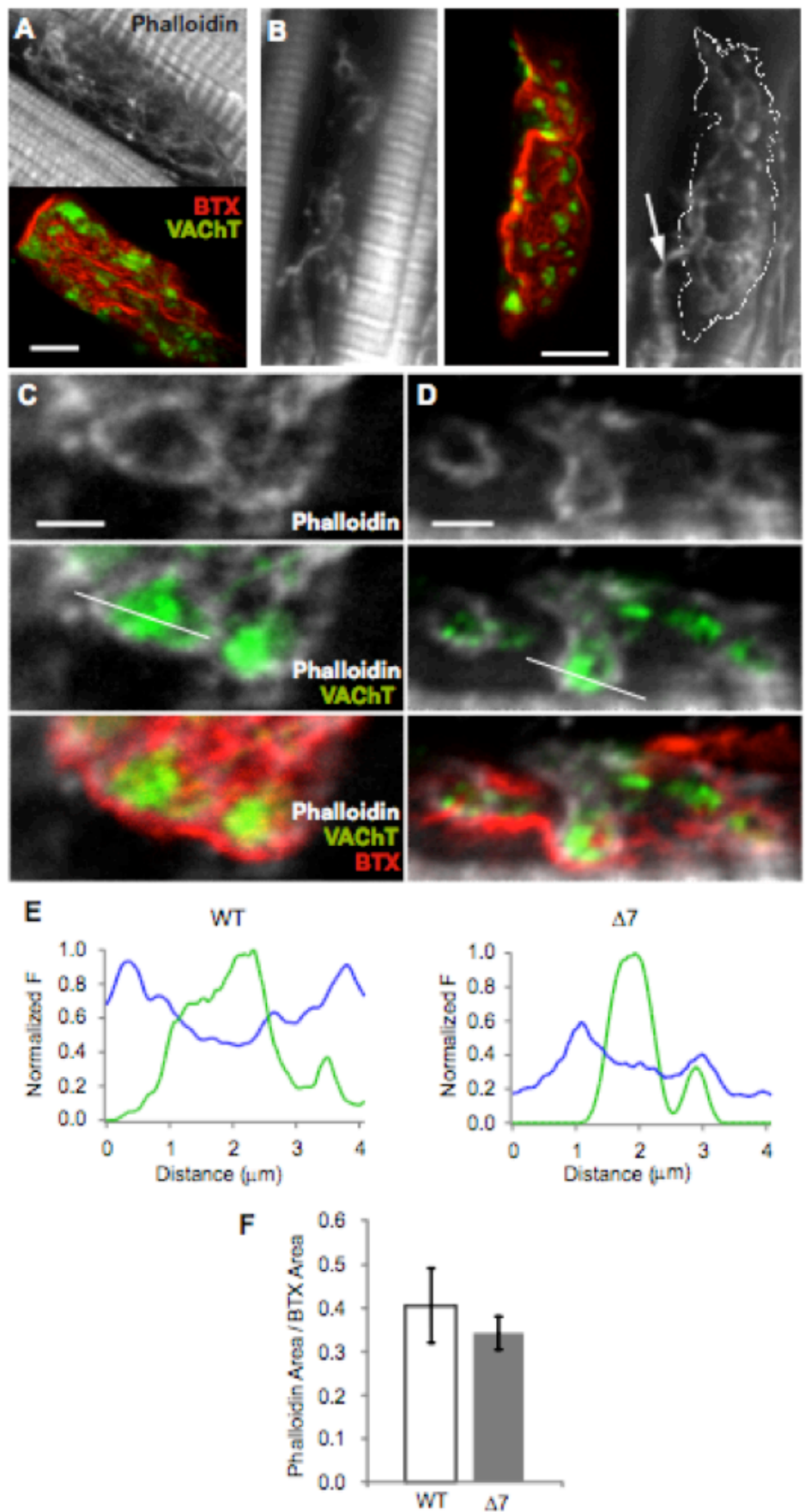

Figure 17: F-actin and SV are closely associated in SMA motor terminals. Data are from the TVA muscle (P14). A - B. Representative examples of the distribution of F-actin (gray) in a WT (A) and a mutant (B) terminal. The same terminals are also shown stained for SV (green) and postsynaptic receptors (red). Arrow in the right panel of B points to actin in the axon. C - D. Phalloidin (blue), SV (green), and AChRs stained with BTX-Rho (red), showing the organization of actin around SV clusters in a WT and a mutant (D) terminal. E. Intensity profiles across actin loops and SV clusters showing the reduced diameter and thickness of the loop in mutants. F. Phalloidin areas in WT and mutant terminals were not significantly different $(P<0.05)$. Scale bars: $A$ \& $B$ : $5 \mu \mathrm{m}$; C \& D: $2 \mu \mathrm{m}$ (from our publication Torres-Benito L, Neher MF, Cano R, Ruiz R, Tabares L., 2011). 


\section{Chapter 4}

\section{Discussion}

Spinal muscular atrophy (SMA), a frequent neurodegenerative disease, is caused by reduced levels of functional SMN. SMN is a ubiquitously expressed protein, however reduced levels of SMN predominantly affect motor neurons and muscles.

The following studies revealed important insights to understand this phenomena:

- In search of a neuron-specific function of SMN it was shown that SMN interacts with $\beta$-actin mRNA and mediates its transport along the axon (Rossoll et al 2003).

- Functional studies at neuromuscular junctions (NMJ) showed that the evoked neurotransmitter release was decreased by approximately $55 \%$ in most affected muscles, indicating a decreased number of fused vesicles, while asynchronous release is increased by $\sim 300 \%$ due to an anomalous accumulation of intraterminal bulk $\mathrm{Ca}^{2+}$ in SMA mice (Ruiz et al 2010). A possible explanation of this augmentation is a decreased $\mathrm{Ca}^{2+}$ reuptake by mitochondria during trains of action potential.

Starting from these results, here, we undertook a manifold morphological study regarding synaptic vesicles (SVs), mitochondria and actin at the NMJ of SMN deficient mice in order to better understand the disturbed neurotransmission mentioned above and to learn more about actin as a possible key player in SMA pathogenesis.

\subsection{Synaptic Vesicle Clusters remain small in SMA mice during Maturation}

Our fluorescence microscopy images using an antibody against the vesicular acetylcholine transporter (vAChT) show clearly, that synaptic vesicles are organized in clusters in the presynaptic motor terminal.

We demonstrated that in wild type muscles, as a pattern of maturation, the SV clusters increased highly in size while their number diminished between P7 and P14. In mutant mice, however, the clusters remained small and the number of clusters did not change. Hence at P7 the total surface of the terminal covered by SV and the average size of any 
given cluster was equally reduced by $\sim 30 \%$ in mutant mice. At P14 these differences became even larger, while in littermate controls the cluster size increased, and the number of clusters diminished. In mutants no change in cluster size, nor in the number of clusters per terminal, took place. In numbers, at P14 the total surface of the terminal covered by SV was near 50\%, and the size of SVclusters was $\sim 75 \%$ reduced in mutant mice. This is in agreement with an electron microscopy study of NMJ in tibialis anterior muscle at P13 demonstrating that individual synaptic vesicles within the presynaptic terminal had normal diameter and morphology, but their overall density within the presynaptic terminal area was reduced by $56 \%$ (Kong et al 2009). Accordingly, another ultrastructal study showed a decrease in SV density in SMA mice (Lee et al 2011). In contrast in diaphragm at P14 no significant difference in vesicle number was found (Kariya et al 2009). The finding that the size of SV clusters increases during maturation leads to the question whether single vesicles increase in size, their density within clusters decreases, or the number of vesicles increases. The amplitude of spontaneous miniature endplate currents (mEPC), representing the muscle response to neurotransmitter release from a single vesicle, was found to be normal in SMA mice. This indicates that the size of single vesicles is normal and suggests that a reduced number of vesicles or increased vesicle density leads to the smaller SV cluster size (Kong et al 2009).

However our images provide only information about the area of maximum projections of SV clusters. Also, light-microscopic images of clusters do not provide numbers on the density of vesicles within clusters. Disregarding such problems and assuming tightest possible vesicle packing a very rough estimation on how many SV might form one SV cluster can be obtained by dividing the volume of a sphere with the diameter of one SV cluster $(2.6 \mu \mathrm{m}$, in wild type TVA at P14) by the volume of one vesicle $(0.0395 \mu \mathrm{m}$ in diameter). Doing so we arrive at a very high number - 285000. This is orders of magnitude larger than estimates from electron microscopic studies on the number of vesicles per active zone for mammalian glutamatergic synapses (200 to 250). It is, however, compatible with estimates in ribbon synapses (10000 to 13000), if a volume fraction of about 0.05 is assumed (see (Fernndez-Alfonso and Ryan 2006), 2006, for a review on vesicle numbers). Under the same assumption the total vesicle pool in frog neuromuscular junction contains $\sim 500,000$ vesicles ((Ceccarelli et al 1973); (Heuser and Reese 1973); (Molgo and Pecot-Dechavassine 1988); (Rizzoli and Betz 2005)). We could show that the area of the cluster size increases three times from P7 to P14 in wild type TVA, which would mean a 5.2 times increase in the number of vesicles at constant packing density. In contrast in SMA mice the cluster size remains almost the same from P7 to P14.

However, repeating similar experiments using a fluorescent microscope with a resolution high enough to identify single vesicles or else an electronmicroscopic analysis would certainly be an interesting extension of our study. 


\subsection{Selective Vulnerability of Motor Neurons inner- vating the Caudal Band of Levator Auris Longus muscle (LAL) despite only modest Abnormalities at the Postsynaptic Side}

To study SV in a different anatomical region we perfomed the same analysis we did in TVA muscle in LAL muscle. In LAL muscle we showed that SV pathology is more severe in the caudal band than in the rostral band. There was no differences between mutant and wild type regarding the SV area and mean size of SV clusters in the rostral band at P7, while both parameters were significantly reduced in mutants at P14. On the contrary, in the caudal band both parameters were already decreased at P7. The reduction in the caudal band of the area covered by SV and mean size of SV clusters was even more profound than in TVA muscle.

These results, identifying the caudal band to be more affected in the disease than the rostral band, is in agreement with a study showing that presynaptic nerve terminal loss was widespread in the caudal band but almost absent in the rostral band (Murray et al 2008). After excluding other possibilities, it is likely that this selective vulnerability in the caudal band is due to the Fast Synapsing (FaSyn) characteristic, while in rostral band the Delayed Synapsing (DeSyn) characteristic is dominant (Murray et al 2008). However this does not demonstrate a direct link between FaSyn characteristics and selective vulnerability since genetic tools to experimentally manipulate FaSyn and DeSyn characterestics are not available yet. To get more insight into the question what makes some muscles more vulnerable than others, it would be of interest to proof whether also the TVA belongs to the class of Fast Synapsing muscles.

The comparison of postsynaptic sizes revealed that the reduction at the postsynaptic side is much more profound in TVA than in LAL. This is in agreement with a study showing that the reduction of muscle fiber diameter and postsynaptic endplate shrinkage was profound in TVA, but only modest in LAL (Murray et al 2008). For a better understanding of the disease it is essential to define whether postsynaptic pathology at the NMJ is a consequence of pathology of the nerve or occurs independently from presynaptic pathology.

In case postsynaptic pathology is a consequence of presynaptic pathology we would expect that abnormalities at the postsynaptic side are correlated to pre- synaptic abnormalities. Here we could show, however, that in the caudal band of LAL a marked reduction of the pool size of SV is present in the presynapse, despite only modest abnormalities of its postsynaptic side. This finding suggests that postsynaptic pathology occurs largely independently from presynaptic pathology. According to that it was shown that presynaptic nerve terminal loss can occur independently from postsynaptic endplate shrinkage at the neuromuscular junction (Murray et al 2008). Thus, it is unlikely that postsynaptic pathology is a plain consequence of disturbed neuronal signaling. One possible explanation for this is that perturbed SMN gene activity may be required in both neuronal and muscle tissue to result in the pathological phenotype (Chan et al 2003). Neuron-specific functions 
of SMN are well documented with SMN being shown to be important for events including axon outgrowth, pathfinding, and neuronal maintenance ((McWhorter et al 2003); $($ Rossoll et al 2003); (Ferri et al 2004)).

The muscle-specific role is still not comprehensively explored. Deletion of SMN exon 7 in mouse muscle is known to cause severe muscular dystrophy (Cifuentes-Diaz et al 2001) and a recent study, utilizing a drosophila model of SMA, has identified an important role for the SMN protein in specifying form and function of muscle sarcomeres (Rajendra et al 2007). Accordingly, a study in SMA mice shows that the molecular profile of muscle pathology in SMA, with an upregulation of voltage-dependent anion-selective protein 2 (Vdac2) and downregulation of parvalbumin, was distinct from that of denervated muscle. This adds further to the hypothesis that SMN-induced changes in muscle cannot solely be attributed to motor neuron degeneration (Mutsaers et al 2011).

One possibility to better clarify to what extend pre- and postpathology are interrelated would be to repeat the current set of experiments in a mouse model, in which SMN expression has been reduced specifically either in muscle or nerve tissue.

\subsection{Mitochondrial Clusters are smaller in SMA Mo- tor Terminals}

We could show that mitochondria are organized in clusters and that the number of clusters per terminal is the same in mutant and wild type at P14. However the mean size of clusters was reduced by about one half in mutants and accordingly the total area of mitochondrial clusters per terminal was $\sim 50 \%$ reduced in mutants.

Little is known about the role of mitochondria in SMA pathogenesis. In one electron microscopy (EM) study on P14 SMA mice presynaptic mitochondria in diaphragmatic muscle are decreased in size but not in numbers (Kariya et al. 2008). In contrast, another electron microscopy study on P14 SMA mice showed in Tibiales Anterior muscle a reduced density of mitochondria, while mitochondrial morphology was normal (Kong et al 2009). Therefore it remains unclear, whether our finding of a reduced size of mitochondrial clusters is due to smaller mitochondria or reduced number of mitochondria in SMA mice. The staining of mitochondria with the fluorescent dye Mito Tracker is problematic: the uptake of Mito Tracker into mitochondria depends on the negative resting membrane potential. Therefore mitochondria had to be in a fairly viable condition to achieve specific staining. We had to exclude many preparations from further analysis because Mito Tracker did not enter sufficiently into the mitochondria.

On the other hand, although the Mito Tracker signal does not provide information about the functionality of mitochondria in all aspects, one advantage of this probe is that it does confirm that mitochondria are still active to maintain a negative resting membrane potential. Hence we could compare the amount of active mitochondria in mutant and wild type.

Mitochondrial dysfunction is known to play a central role in the pathogenesis of ma- 
jor neurodegenerative diseases such as Alzheimer's, Parkinson's, Huntington's disease, and amytrophic lateral sclerosis. This is not surprising regarding the two faces of mitochondria. Besides being sources of ATP, mitochondria are also the main producers of reactive oxygen species (ROS). If ROS levels overwhelm the defense mechanisms of the cells, oxidative damage of proteins, lipids, and DNA occurs ((Valko et al 2007); (Carvalho et al 2009)). Another consequence of mitochondrial impairment is the release of pro-apoptotic factors and a reduced $\mathrm{Ca}^{2+}$ buffering capacity. At the presynaptic side rapid recovery of $\mathrm{Ca}^{2+}$ transients is essential for nerve signaling. Interestingly at NMJ of SMA mice the asynchronous neurotransmitter release (see introduction) was found to be increased by $\sim$ $300 \%$ indicating an anomalous augmentation of intraterminal bulk $\mathrm{Ca}^{2+}$ during repetitive stimulation (Ruiz et al 2010).

Permanent $\mathrm{Ca}^{2+}$ overload is toxic for the cell as a result of several cross-amplifying cascades, which will be briefly mentioned here. First, $\mathrm{Ca}^{2+}$ activates the cysteine proteases of the calpain and caspase families, that degrade a variety of substrates and trigger apoptotic cascades ((Chan and Mattson|1999); (Nixon|2003)). Second, $\mathrm{Ca}^{2+}$ induces oxidative stress, among others through the activation of oxygenases (Lipton, 1993; Mattson and Pedersen, 1998). Third, $\mathrm{Ca}^{2+}$ triggers apoptosis through activation of pro-apototic proteins such as Bax, Par-4, and p53 leading to mitochondrial membrane permeability changes, release of cytochrome C, and caspase activation ((Duan and Cooke 1999); (Dargusch et al 2001); (Culmsee and Mattson 2005).

Regarding the finding of $\mathrm{Ca}^{2+}$ accumulation at the presynaptic side of SMA mice and the obliterative effect of $\mathrm{Ca}^{2+}$ overload on the cell in general, it is obvious that answering the question how $\mathrm{Ca}^{2+}$ accumulation comes about in SMA might provide an important step towards a possible therapy of the disease. At the presynaptic side, the influx of $\mathrm{Ca}^{2+}$ through voltage-dependent and ligand-gated channels in the plasma is a critical signal for the release of neurotransmitters ((Yuste et al 2000); (Burnashev and Rozov 2005)).

Normally, $\mathrm{Ca}^{2+}$ is then removed from the cytoplasm by plasma membrane $\mathrm{Na}+/ \mathrm{Ca}^{2+}$ exchanger, plasma membrane and ER $\mathrm{Ca}^{2+}$-ATPase, as well as $\mathrm{Ca}^{2+}$-binding proteins such as calbindin and parvalbumin (Hof et al 1999). Moreover, $\mathrm{Ca}^{2+}$ can be transported into and released from mitochondria ((Werth et al 1994); (Duchen 2000); (Nicholls|2003)). This raises the question to what extend mitochondrial dysfunction contributes to the altered $\mathrm{Ca}^{2+}$ homeostasis in SMA. Here we could show that the amount of active mitochondria is about half in mutants. Further work is required to find out whether the remaining mitochondria still function in their role to regulate intraterminal $\mathrm{Ca}^{2+}$ levels. This could be addressed through intramitochondrial $\mathrm{Ca}^{2+}$ measurements upon stimulation using $\mathrm{Ca}^{2+}$ -sensitive fluorescent indicator dyes (Vila et al 2003). 


\subsection{SV Clusters and Mitochondria are localized in Pairs}

Surprisingly our confocal images with a double staining of SV and Mitochondria revealed that SV cluster are localized right next to mitochondrial cluster (Fig. 16). In many cases SV were scattered around a core of mitochondria forming a ring-like structure. Quantification of the nearest neighbor distances confirmed this observation and showed that this aspect of spatial organization is not altered in mutant terminals. Similar to our finding, SV has been described to form donut-like assemblies around a central cluster of mitochondria in the calyx of Held synapse. Further estimation assume that each of this units consist out of $\sim 800$ synaptic vesicles and six to nine mitochondria (Wimmer et al 2006).

In the calyx of Held this structural specialization appeared with the onset of hearing which was accompanied by distinct changes in the properties of synaptic transmission. After the onset of hearing, mature synapses show much less short-term synaptic depression, low release probabilities, and narrow action potentials (Taschenberger and von Gersdorff, 2000; Taschenberger et al., 2002). It is therefore likely that the pairing from SV clusters and mitochondria is tightly linked to enhanced synaptic function both in the calyx of Held and probably also in the NMJ. As a consequence the ATP, produced by mitochondria, could be directly and more efficiently used for priming, transport, and filling of SVs. Moreover mitochondria might be perfectly located to fulfill their role as $\mathrm{Ca}^{2+}$ buffer, which is essential for sustaining high-frequency synaptic transmission. Taken together, we here show, to our knowledge for the first time at the NMJ, that SV clusters are colocalized with mitochondria. This provides evidence that the structural principle described in the calyx of Held might be of more general relevance for pre-synaptic terminals.

\subsection{Actin Dynamics in SMA Pathogenesis}

The finding, that the SMN protein is involved in the transport of $\beta$-actin mRNA along the axon, raises the question to what extent a disturbance of the actin cytoskelton influences the pathogenesis in SMA (Rossoll et al 2003).

For our fluorescent microscopy study we labeled $\beta$-actin with phalloidin and the postsynaptic side with BTX-Rhodamine in TVA muscle at P14. In addition, to gain insight into the role of $\beta$-actin in the organization of SV, we labeled SV with VAChT antibodies. Our images showed that $\beta$-actin is localized in the sub-plasmalemmal region and extends deep into the cytoplasm forming a thin network. Interestingly, single confocal slices revealed that -actin surrounds SV clusters forming ring-like structures. Similarly, in the lamprey giant synapse and hippocampal synaptic terminals actin was described to form ring-like structures around SV clusters (Shupliakov et al. 2002; Sankaranarayanan et al. 2003).

To our knowledge it is the first time that this organization of actin forming ring-like structures around SV is described at the NMJ of WT mice and we could show that this organization pattern was equally found in SMA mice. However the diameter of -actin rings surrounding SV appeared smaller in mutant than in WT terminals, as could be estimated 
by respective line intensity profiles across SV and phalloidin loops. Moreover, we showed that in WT mice the area of the terminal covered by phalloidin was apparently larger than in mutants (WT: $41 \pm 9 \%, \mathrm{n}=6$ terminals; mutants: $34 \pm 4 \%, \mathrm{n}=6$ terminals). However this difference did not reach statistical significance $(\mathrm{P}=0.5)$.

A decreased actin content in SMA nerve terminals would be in agreement with the reduced $\beta$ actin protein and mRNA staining in growth cones in culture (Rossoll et al 2003). Compatible to the proposed function of SMN in the transport of $\beta$-actin mRNA along the axon, it was shown that there is a significant reduction of actin signals in the distal axon, and growth cone of SMN deficient motor neurons compared to the wild type, whereas in the soma no significant difference to the wild type has been found (Mayer 2009). In addition it was shown that treatment of Smn -/-; SMN2 motor neurons in culture by cyclic adenosinmonophosphate (cAMP) induces increases of SMN protein in the soma, axon, and growth cones. This could be explained by the presence of a CREII binding element in the SMN promotor region, which mediates effects of cAMP and therefore stimulates the SMN-transcription of the examined cells. Interestingly, along with the increase of SMN protein in cAMP treated SMN -/-; SMN2 motor neuron an increase of the $\beta$-actin signal in the distal axon and growth cone compared to untreated cells was found (Mayer 2009). This adds further weight to the supposition that a deficit in SMN protein, which underlies SMA, leads to a disruption of the actin cytoskeleton. Synaptic efficacy depends in multiple ways on the actin cytoskeleton: Using an actin depolymerizing agent, latrunculin A, it could be shown that actin is essential for the development and maintenance of young synapses, defined by synaptophysin-labeled vesicle clusters, synaptic vesicle recycling, and ultrastructure. Also, it is proposed that actin, because it is so highly regulated, is a principal target for stabilizing or destabilzing signals that ultimately determine synapse maintenance or elimination (Zhang and Benson 2001). Moreover actin seems to serve as a molecular scaffold to increase the local concentration of an important regulatory molecule, synapsin, in the vicinity of the presynaptic vesicle cluster (Sankaranarayanan et al 2003). Synapsin, a soluble protein of the synaptic terminal, is regulated through phosphorylation and dephosphorylation. Synapsin forms a link between synaptic vesicles and actin (Greengard et al 1993). After vesicle fusion, synapsin disassociates from synaptic vesicles due to its curvature-sensing ALS-motif (Krabben et al 2011). Synapsin then accumulates in the endocytic region and interacts with a soluble pool of G-actin, where the actin-rich cytomatrix is formed. Then synapsin reassociates with vesicle membranes (Bloom et al 2003). Together with synapsin actin has been implicated at multiple steps of the synaptic vesicle cycle, including endocytosis, transport of recycled vesicles to the synaptic vesicle cluster, and exocytosis (Shupliakov et al 2002).

Regarding this multiple functions of actin in the vesicle cycle it appears plausible that disorganization in the actin cytoskeleton can affect SV and further neurotransmission.

In the present work we demonstrate that SV clusters remain small during maturation and the total area of the terminal covered by vesicles is reduced by about $50 \%$ in mutant mice at P14. This is accompanied by a decrease of evoked neurotransmission by $55 \%$ and a two fold reduction of the evoked endplate signals (Kong et al. 2009; Ruiz et al. 2010). Besides the reduction of SV vesicles we could show that mitochondria are organized in clusters 
next to SV clusters at the NMJ. The total area covered by mitochondria per terminal was $\sim 50 \%$ reduced in mutants. Axonal transport of mitochondria is ensured by microtubulebased motors whereas short range movement of vesicles and organelles at growth cones and nerve terminals depends primarily on actin-myosin-based transport (Langford 2002). The interaction between microtubule-and actin-based motors suggests that mitochondrial transport can be coordinated along both cytoskeletal systems (Bridgman 2004). These tight interactions seem to be controlled through complex phosphorylation processes of motor proteins, cytoskeletal structures, or mitochondrial membrane proteins (Müller et al 2005).

In conclusion, actin strongly interacts with SV and mitochondria. Also other characteristics of the disease phenotype, like for example reduced axon growth and branching ((Rossoll et al 2003); (Kariya et al 2009)), are highly actin-dependent mechanisms. Interestingly, in order to explain the tissue-specific nature of SMA, the only neuron specific function of the SMN protein which could be identified is that SMN mediates the transport of $\beta$-actin mRNA along the axon. It remains to be determined, whether SMN also mediates the transport of other mRNA species. Above all, further work is required to clarify whether the characteristics of the disease phenotype described here, such as abnormal SV clustering and reduction of mitochondria, occur independently or are the consequence of a dysfunction of the cytoskeleton, which would assign a key role in SMA pathogenesis to actin. 


\section{Chapter 5}

\section{Abstract}

Proximal spinal muscular atrophy (SMA) is an autosomal recessive disorder characterized by degeneration of the second motor neurons and progressive paralysis with atrophy of the proximal muscles. After cystic fibrosis, SMA is the most common autosomal recessive disorder in humans and the most common genetic cause for infant mortality. SMA, monogenic in origin, is caused by a mutation in a single gene, the Survival of Motor Neuron 1 (SMN1) gene, which leads to reduced levels of Survival Motor Neuron (SMN) protein. SMN is a ubiquitously expressed protein with house-keeping roles in snRNP biogenesis and pre-mRNA splicing. However, reduced levels of SMN predominantly affect motor neurons and muscles for reasons that are poorly understood. It was shown that SMN interacts with $\beta$-actin mRNA and mediates its transport along the axon. Functional studies at neuromuscular junctions (NMJ) revealed that the evoked neurotransmitter release was decreased by approximately $55 \%$ in most affected muscles, indicating a decreased number of fused vesicles, while asynchronous release is increased by $\sim 300 \%$ due to an anomalous accumulation of intraterminal bulk $\mathrm{Ca}^{2+}$ in SMA mice. A possible explanation of this augmentation is a decreased $\mathrm{Ca}^{2+}$ reuptake by mitochondria during trains of action potential.

This study presents a comprehensive fluorescent confocal microcopy analysis of the organization and abundance of synaptic vesicles (SVs), mitochondria, and actin in nerve terminals of SMA mice (Smn -/-; SMN2; SMN $\Delta$ ). The results are also part of our joint publication of Torres-Benito L, Neher MF, Cano R, Ruiz R, Tabares L (2011) SMN Requirement for Synaptic Vesicle, Active Zone and Microtubule Postnatal Organization in Motor Nerve Terminals. PlosOne 6(10):e26164.doi:10.1371/journal.pone.0026164. We visualized SV clusters with an antibody against the vesicular acetylcholine transporter (VAChT) and could show that in Transversus abdominis (TVA) muscle SV clusters remain small during maturation with the total area covered by SVs reduced by $\sim 50 \%$. This severe reduction of SVs was also found in the caudal band of the Levator auris longus muscle (LAL). However, only modest abnormalities at the postsynaptic side were detectable in this muscle. This finding of presynaptic pathology, despite an almost normal postsynaptic status, supports the hypothesis that SMN-induced changes in muscle cannot be solely attributed to motor neuron degeneration.

Next, we stained mitochondria with Mito Tracker and found that the area covered by 
mitochondria in mutants was about half compared to wild type. Surprisingly SVs and mitochondria were strongly colocalized. In many cases a core of mitochondria was clearly surrounded by a SV rim. This spatial organization was not altered in mutants and might be of general relevance for the functional integrity in nerve terminals.

Phalloidin stains of F-actin showed that F-actin forms ring-like structures around SV clusters. These structures and the percentage of the terminal area covered by actin, normalized to the postsynaptic area, were smaller in mutant mice.

Actin is implicated at multiple steps of the synaptic vesicle cycle. Short range movement of vesicles and organelles, such as mitochondria at growth cones and nerve terminals, depends primarily on actin-myosin-based transport. Further work is required to clarify whether the characteristics of the disease phenotype described here, such as abnormal SV clustering and reduction of mitochondria, occur independently or are the common consequence of dysfunction of the actin cytoskeleton, which would assign a key role in SMA pathogenesis to actin. 


\section{Bibliography}

Béchade C, Rostaing P, Cisterni C, Kalisch R, La Bella V, Pettmann, B, Triller, A (1999): Subcellular distribution of survival motor neuron (SMN) protein: possible involvement in nucleocytoplasmic and dendritic transport. Eur J Neurosci, 11(1), 293-304

Bertrandy S, Burlet P, Clermont O, Huber C, Fondrat C, Thierry-Mieg, D, Munnich A, Lefebvre, S (1999): The RNA-binding properties of SMN: deletion analysis of the zebrafish orthologue defines domains conserved in evolution. Hum Mol Genet, $\underline{8}(5), 775-782$

Bloom O, Evergren E, Tomilin N, Kjaerulff O, Löw P, Brodin L, Pieribone V A, Greengard P, Shupliakov, O (2003): Colocalization of synapsin and actin during synaptic vesicle recycling. J Cell Biol, 161(4), 737-747

Bowerman M, Anderson C L, Beauvais A, Boyl P P, Witke W, Kothary, R (2009): SMN, profilin IIa and plastin 3: a link between the deregulation of actin dynamics and SMA pathogenesis. Mol Cell Neurosci, $\underline{42}(1), 66-74$

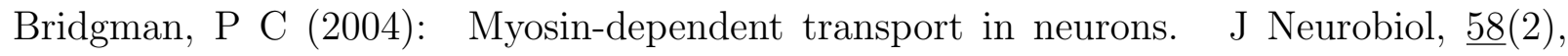
$164-174$

Briese M, Esmaeili B, Sattelle, D B (2005): Is spinal muscular atrophy the result of defects in motor neuron processes? Bioessays, 27(9), 946-957

Bühler D, Raker V, Luhrmann R, Fischer, U (1999): Essential role for the tudor domain of SMN in spliceosomal U snRNP assembly: implications for spinal muscular atrophy. Human molecular genetics, $\underline{8}(13), 2351-7$

Burlet P, Huber C, Bertrandy S, Ludosky M A, Zwaenepoel I, Clermont, O, Roume J, Delezoide A L, Cartaud J, Munnich A, Lefebvre, S (1998): The distribution of SMN protein complex in human fetal tissues and its alteration in spinal muscular atrophy. Hum Mol Genet, $7(12), 1927-1933$

Burnashev, N and Rozov, A (2005): Presynaptic $\mathrm{Ca}^{2+}$ dynamics, $\mathrm{Ca}^{2+}$ buffers and synaptic efficacy. Cell calcium, 37(5), 489-95

Carissimi C, Saieva L, Baccon J, Chiarella P, Maiolica A, Sawyer A, Rappsilber J, Pellizzoni, L (2006): Gemin8 is a novel component of the survival motor neuron complex and functions in small nuclear ribonucleoprotein assembly. J Biol Chem, 281(12), 8126-8134 
Carvalho C, Correia S C, Santos, R X, Cardoso S, Moreira P I, Clark T A, Zhu, X, Smith M A, Perry, G (2009): Role of mitochondrial-mediated signaling pathways in alzheimer disease and hypoxia. J Bioenerg Biomembr, $\underline{41}(5), 433-440$

Carvalho T, Almeida F, Calapez A, Lafarga M, Berciano M T, Carmo-Fonseca, M (1999): The spinal muscular atrophy disease gene product, SMN: a link between snRNP biogenesis and the cajal (coiled) body. J Cell Biol, 147(4), 715-728

Ceccarelli B, Hurlbut W P, Mauro, A (1973): Turnover of transmitter and synaptic vesicles at the frog neuromuscular junction. The Journal of cell biology, 57(2), 499-524

Chan, S L and Mattson, M P (1999): Caspase and calpain substrates: roles in synaptic plasticity and cell death. The international journal of biochemistry \& cell biology, $\underline{58}(1)$, $167-90$

Chan, Y B, Miguel-Aliaga I, Franks C, Thomas N, Trülzsch B, Sattelle D B, Davies K E, van den Heuvel, M (2003): Neuromuscular defects in a Drosophila survival motor neuron gene mutant. Hum Mol Genet, 12(12), 1367-1376

Charroux B, Pellizzoni L, Perkinson R A, Yong J, Shevchenko A, Mann, M, Dreyfuss, G (2000): Gemin4 a novel component of the SMN complex that is found in both gems and nucleoli. J Cell Biol, 148(6), 1177-1186

Cifuentes-Diaz C, Frugier T, Tiziano F D, Lacène E, Roblot N, Joshi V, Moreau M H, Melki, J (2001): Deletion of murine SMN exon 7 directed to skeletal muscle leads to severe muscular dystrophy. J Cell Biol, 152(5), 1107-1114

Coovert D D, Le T T, McAndrew P E, Strasswimmer J, Crawford, T O, Mendell J R, Coulson S E, Androphy E J, Prior T W, Burghes, A H (1997): The survival motor neuron protein in spinal muscular atrophy. Hum Mol Genet, $\underline{6}(8), 1205-1214$

Culmsee, C and Mattson, M P (2005): p53 in neuronal apoptosis. Biochemical and biophysical research communications, $\underline{331}$ (3), 761-77

Dargusch R, Piasecki D, Tan S, Liu, Y, Schubert, D (2001): The role of Bax in glutamateinduced nerve cell death. Journal of neurochemistry, 76(1), 295-301

David, G and Barrett, E F (2000): Stimulation-evoked increases in cytosolic [ca(2+)] in mouse motor nerve terminals are limited by mitochondrial uptake and are temperaturedependent. J Neurosci, 20(19), 7290-7296

De Camilli P, Benfenati F, Valtorta F, Greengard, P (1990): The synapsins. Annual review of cell biology, $\underline{6}: 433-60$

DiDonato C J, Chen, X N, Noya D, Korenberg J R, Nadeau J H, Simard, L R (1997): Cloning, characterization, copy number of the murine survival motor neuron gene: homolog of the spinal muscular atrophy-determining gene. Genome research, $\underline{7}(4), 339-52$ 
Dreesen J C, Bras M, de Die-Smulders C, Dumoulin J C, Cobben J M, Evers J L, Smeets H J, Geraedts, J P (1998): Preimplantation genetic diagnosis of spinal muscular atrophy. Molecular Human Reproduction, $\underline{4}(9), 881-5$

Duan, S and Cooke, I M (1999): Selective inhibition of transient K+ current by La3+ in crab peptide-secretory neurons. Journal of neurophysiology, 81(4), 1848-55

Duchen, M R (2000): Mitochondria and Ca(2+)in cell physiology and pathophysiology. Cell calcium, 28 (5-6), 339-48

Fan, L and Simard, L R (2002): Survival motor neuron (SMN) protein: role in neurite outgrowth and neuromuscular maturation during neuronal differentiation and development. Hum Mol Genet, 11(14), 1605-1614

Feldkötter M, Schwarzer V, Wirth R, Wienker T F, Wirth, B (2002): Quantitative analyses of SMN1 and SMN2 based on real-time lightCycler PCR: fast and highly reliable carrier testing and prediction of severity of spinal muscular atrophy. American journal of human genetics, $\underline{70}(2), 358-68$

Fernndez-Alfonso, T and Ryan, T A (2006): The efficiency of the synaptic vesicle cycle at central nervous system synapses. Trends Cell Biol, 16(8), 413-420

Ferri A, Melki J, Kato, A C (2004): Progressive and selective degeneration of motoneurons in a mouse model of SMA. Neuroreport, $\underline{15}(2), 275-280$

Fischer U, Liu Q, Dreyfuss, G (1997): The SMN-SIP1 complex has an essential role in spliceosomal snRNP biogenesis. Cell, $\underline{90}(6), 1023-1029$

Friesen, W J and Dreyfuss, G (2000): Specific sequences of the sm and sm-like (lsm) proteins mediate their interaction with the spinal muscular atrophy disease gene product (SMN). J Biol Chem, 275(34), 26370-26375

Gall J G, Bellini M, Wu, Z, Murphy, C (1999): Assembly of the Nuclear Transcription and Processing Machinery: Cajal Bodies (Coiled Bodies) and Transcriptosomes. Molecular Biology of the Cell, 10:4385-4402

Giavazzi A, Setola V, Simonati A, Battaglia, G (2006): Neuronal-specific roles of the survival motor neuron protein: evidence from survival motor neuron expression patterns in the developing human central nervous system. J Neuropathol Exp Neurol, $\underline{65}(3), 267-$ 277

Girard C, Neel H, Bertrand E, Bordonné, R (2006): Depletion of SMN by RNA interference in HeLa cells induces defects in cajal body formation. Nucleic Acids Res, 34(10), 2925-2932

Govek, E-E, Newey S E, Van Aelst, L (2005): The role of the rho GTPases in neuronal development. Genes Dev, 19 $(1), 1-49$ 
Greene, E C: Anatomy of the rat. American Philosophical Society Transactions, new series; no27 Hafner Reprint 1955

Greengard P, Valtorta F, Czernik A J, Benfenati, F (1993): Synaptic vesicle phosphoproteins and regulation of synaptic function. Science, 259(5096), 780-785

Gubitz A K, Feng W, Dreyfuss, G (2004): The SMN complex. Exp Cell Res, 296(1), $51-56$

Hannus S, Bühler D, Romano M, Seraphin B, Fischer, U (2000): The schizosaccharomyces pombe protein yab8p and a novel factor, yip1p, share structural and functional similarity with the spinal muscular atrophy-associated proteins SMN and SIP1. Hum Mol Genet, $\underline{9}(5), 663-674$

Heuser, J E and Reese, T S (1973): Evidence for recycling of synaptic vesicle membrane during transmitter release at the frog neuromuscular junction. The Journal of cell biology, $\underline{57}(2), 315-44$

Hirokawa N, Sobue K, Kanda K, Harada A, Yorifuji, H (1989): The cytoskeletal architecture of the presynaptic terminal and molecular structure of synapsin 1. J Cell Biol, $\underline{108}(1), 111-126$

Hirokawa, N and Takeda, S (1998): Gene targeting studies begin to reveal the function of neurofilament proteins. J Cell Biol, 143(1), 1-4

Hof P R, Glezer I I, Condé F, Flagg R A, Rubin M B, Nimchinsky, E A, Vogt Weisenhorn, D M (1999): Cellular distribution of the calcium-binding proteins parvalbumin, calbindin, calretinin in the neocortex of mammals: phylogenetic and developmental patterns. J Chem Neuroanat, $\underline{16}(2), 77-116$

Hsieh-Li H M, Chang J G, Jong, Y J, Wu M H, Wang N M, Tsai, C H, Li, H (2000): A mouse model for spinal muscular atrophy. Nature genetics, 24(1), 66-70

Jablonka S, Beck M, Lechner B D, Mayer C, Sendtner, M (2007): Defective ca2+ channel clustering in axon terminals disturbs excitability in motoneurons in spinal muscular atrophy. J Cell Biol, 179(1), 139-149

Jones K W, Gorzynski K, Hales C M, Fischer U, Badbanchi F, Terns, R M, Terns, M P (2001): Direct interaction of the spinal muscular atrophy disease protein SMN with the small nucleolar RNA-associated protein fibrillarin. J Biol Chem, 276(42), 38645-38651

Kariya S, Mauricio R, Dai, Y, Monani, U R (2009): The neuroprotective factor wld(s) fails to mitigate distal axonal and neuromuscular junction (NMJ) defects in mouse models of spinal muscular atrophy. Neurosci Lett, $\underline{449}(3), 246-251$

Kolb S J, Battle D J, Dreyfuss, G (2007): Molecular functions of the SMN complex. J Child Neurol, $\underline{22}(8), 990-994$ 
Kong L, Wang, X, Choe D W, Polley M, Burnett B G, Bosch-Marcé M, Griffin J W, Rich M M, Sumner, C J (2009): Impaired synaptic vesicle release and immaturity of neuromuscular junctions in spinal muscular atrophy mice. J Neurosci, 29(3), 842-851

Krabben L, Fassio A, Bhatia V K, Pechstein A, Onofri F, Fadda M, Messa M, Rao, Y, Shupliakov O, Stamou D, Benfenati F, Haucke, V (2011): Synapsin I senses membrane curvature by an amphipathic lipid packing sensor motif. The Journal of neuroscience : the official journal of the Society for Neuroscience, 31(49), 18149-54

Kunze, K: Praxis der Neurologie. Georg Thieme Verlag, Stuttgart 1999

Langford, G M (2002): Myosin-v, a versatile motor for short-range vesicle transport. Traffic, $\underline{3}(12), 859-865$

Le T T, Pham L T, Butchbach, M E R, Zhang H L, Monani U R, Coovert D D, Gavrilina T O, Xing L, Bassell G J, Burghes, A H M (2005): SMNDelta7, the major product of the centromeric survival motor neuron (SMN2) gene, extends survival in mice with spinal muscular atrophy and associates with full-length SMN. Hum Mol Genet, 14(6), 845-857

Lee, Y I, Mikesh M, Smith I, Rimer M, Thompson, W (2011): Muscles in a mouse model of spinal muscular atrophy show profound defects in neuromuscular development even in the absence of failure in neuromuscular transmission or loss of motor neurons. Dev Biol, $\underline{356}(2), 432-444$

Lefebvre S, Bürglen L, Reboullet S, Clermont O, Burlet P, Viollet, L, Benichou B, Cruaud C, Millasseau P, Zeviani, M (1995): Identification and characterization of a spinal muscular atrophy-determining gene. Cell, $\underline{80}(1), 155-165$

Lefebvre S, Burlet P, Liu Q, Bertrandy S, Clermont O, Munnich A, Dreyfuss G, Melki, J (1997): Correlation between severity and SMN protein level in spinal muscular atrophy. Nat Genet, 16(3), 265-269

Liu, Q and Dreyfuss, G (1996): A novel nuclear structure containing the survival of motor neurons protein. EMBO J, 15(14), 3555-3565

Liu Q, Fischer U, Wang F, Dreyfuss, G (1997): The spinal muscular atrophy disease gene product, SMN, its associated protein SIP1 are in a complex with spliceosomal snRNP proteins. Cell, $\underline{90}(6), 1013-1021$

Lorson, C L and Androphy, E J (1998): The domain encoded by exon 2 of the survival motor neuron protein mediates nucleic acid binding. Hum Mol Genet, $\underline{7}(8), 1269-1275$

Lorson C L, Hahnen E, Androphy E J, Wirth, B (1999): A single nucleotide in the SMN gene regulates splicing and is responsible for spinal muscular atrophy. Proc Natl Acad Sci USA, $\underline{96}(11), 6307-6311$ 
Luo L, Lee T, Tsai L, Tang G, Jan, L Y, Jan, Y N (1997): Genghis khan (gek) as a putative effector for drosophila cdc42 and regulator of actin polymerization. Proc Natl Acad Sci USA, 94 (24), 12963-12968

Mayer, C (2009): Zyklisches AMP kompensiert morphologische und funktionelle Defekte in isolierten Smn-defizienten Motoneuronen. Med Diss Würzburg

McAndrew P E, Parsons D W, Simard L R, Rochette C, Ray P N, Mendell J R, Prior T W, Burghes, A H (1997): Identification of proximal spinal muscular atrophy carriers and patients by analysis of SMNT and SMNC gene copy number. American journal of human genetics, $\underline{60}(6), 1411-22$

McGovern V L, Gavrilina T O, Beattie C E, Burghes, A H M (2008): Embryonic motor axon development in the severe SMA mouse. Hum Mol Genet, 17(18), 2900-2909

McWhorter M L, Monani U R, Burghes, A H M, Beattie, C E (2003): Knockdown of the survival motor neuron (Smn) protein in zebrafish causes defects in motor axon outgrowth and pathfinding. The Journal of cell biology, 162(5), 919-31

Meister G, Bühler D, Laggerbauer B, Zobawa M, Lottspeich F, Fischer, U (2000): Characterization of a nuclear 20S complex containing the survival of motor neurons (SMN) protein and a specific subset of spliceosomal sm proteins. Hum Mol Genet, $\underline{9}(13), 1977-1986$

Meister G, Bühler D, Pillai R, Lottspeich F, Fischer, U (2001): A multiprotein complex mediates the ATP-dependent assembly of spliceosomal u snRNPs. Nat Cell Biol, $\underline{3}(11)$, $945-949$

Miguel-Aliaga I, Culetto E, Walker D S, Baylis H A, Sattelle D B, and Davies, K E (1999): The caenorhabditis elegans orthologue of the human gene responsible for spinal muscular atrophy is a maternal product critical for germline maturation and embryonic viability. Hum Mol Genet, $\underline{8}(12)$, 2133-2143

Molgo, J and Pecot-Dechavassine, M (1988): Effects of carbonyl cyanide mchlorophenylhydrazone on quantal transmitter release and ultrastructure of frog motor nerve terminals. Neuroscience, $\underline{24}(2), 695-708$

Monani, U R (2005): Spinal muscular atrophy: a deficiency in a ubiquitous protein; a motor neuron-specific disease. Neuron, $\underline{48}(6), 885-896$

Monani U R, Coovert D D, Burghes, A H (2000): Animal models of spinal muscular atrophy. Hum Mol Genet, $\underline{9}(16), 2451-2457$

Mourelatos, Z, Abel L, Yong J, Kataoka N, Dreyfuss, G (2001): SMN interacts with a novel family of hnRNP and spliceosomal proteins. EMBO J, 20 (19), 5443-5452 
Müller S L, Portwich M, Schmidt A, Utepbergenov D I, Huber O, Blasig I E, Krause, G (2005): The tight junction protein occludin and the adherens junction protein alphacatenin share a common interaction mechanism with ZO-1. The Journal of biological chemistry, $\underline{280}(5), 3747-56$

Murray L M, Comley L H, Thomson D, Parkinson N, Talbot K, Gillingwater, T H (2008): Selective vulnerability of motor neurons and dissociation of pre- and post-synaptic pathology at the neuromuscular junction in mouse models of spinal muscular atrophy. Hum Mol Genet, $\underline{17}(7), 949-962$

Mutsaers C A, Wishart T M, Lamont D J, Riessland M, Schreml J, Comley L H, Murray L M, Parson S H, Lochmuller H, Wirth B, Talbot K, Gillingwater, T H (2011): Reversible molecular pathology of skeletal muscle in spinal muscular atrophy. Human molecular genetics, $\underline{20}(22), 4334-44$

Nicholls, D G (2003): Bioenergetics and transmitter release in the isolated nerve terminal. Neurochemical research, 28 $(10), 1433-41$

Nixon, R A (2003): The calpains in aging and aging-related diseases. Ageing research reviews, 2 (4), 407-18

Pagliardini S, Giavazzi A, Setola V, Lizier C, Di Luca M, DeBiasi, S, Battaglia, G (2000): Subcellular localization and axonal transport of the survival motor neuron (SMN) protein in the developing rat spinal cord. Hum Mol Genet, $\underline{9}(1), 47-56$

Paushkin S, Charroux B, Abel L, Perkinson R A, Pellizzoni L, Dreyfuss, G (2000): The survival motor neuron protein of schizosacharomyces pombe conservation of survival motor neuron interaction domains in divergent organisms. J Biol Chem, 275(31), 23841-23846

Pearn, J (1980): Classification of spinal muscular atrophies. Lancet, $\underline{1}(8174)$, 919-922

Pellizzoni L, Charroux B, Rappsilber J, Mann M, Dreyfuss, G (2001): A functional interaction between the survival motor neuron complex and RNA polymerase II. J Cell Biol, $\underline{152}(1), 75-85$

Perkins G A, Tjong J, Brown J M, Poquiz P H, Scott R T, Kolson, D R, Ellisman M H, Spirou, G A (2010): The Micro-Architecture of Mitochondria at Active Zones: Electron Tomography Reveals Novel Anchoring Scaffolds and Cristae Structured for High-Rate Metabolism. The Journal of neuroscience : the official journal of the Society for Neuroscience, $\underline{30}(3), 10151026$

Peter C J, Evans M, Thayanithy V, Taniguchi-Ishigaki N, Bach I, Kolpak A, Bassell G J, Rossoll W, Lorson C L, Bao, Z-Z, Androphy, E J (2011): The COPI vesicle complex binds and moves with survival motor neuron within axons. Hum Mol Genet, 20(9), 1701-1711

Poeck K, Hacke, W: Neurologie Springer-Verlag, Berlin 2001 
Poot M, Zhang, Y Z, Krämer J A, Wells K S, Jones L J, Hanzel, D K, Lugade A G, Singer V L, Haugland, R P (1996): Analysis of mitochondrial morphology and function with novel fixable fluorescent stains. J Histochem Cytochem, 44(12), 1363-1372

Rajendra T K, Gonsalvez G B, Walker M P, Shpargel K B, Salz H K, and Matera, A G (2007): A drosophila melanogaster model of spinal muscular atrophy reveals a function for SMN in striated muscle. J Cell Biol, $\underline{176}(6), 831-841$

Rizzoli, S O and Betz, W J (2005): Synaptic vesicle pools. Nat Rev Neurosci, $\underline{6}(1)$, 57-69

Rossoll W, Jablonka S, Andreassi C, Kröning, A-K, Karle K, Monani, U R, Sendtner, M (2003): Smn, the spinal muscular atrophy-determining gene product, modulates axon growth and localization of $\beta$-actin mRNA in growth cones of motoneurons. J Cell Biol, $\underline{163}(4), 801-812$

Ruiz R, Casaas J J, Torres-Benito L, Cano R, Tabares, L (2010): Altered intracellular $\mathrm{ca}^{2+}$ homeostasis in nerve terminals of severe spinal muscular atrophy mice. J Neurosci, $\underline{30}(3), 849-857$

Sankaranarayanan S, Atluri P P, Ryan, T A (2003): Actin has a molecular scaffolding, not propulsive, role in presynaptic function. Nat Neurosci, $\underline{6}(2), 127-135$

Schrank B, Götz R, Gunnersen J M, Ure J M, Toyka K V, Smith, A G, Sendtner, M (1997): Inactivation of the survival motor neuron gene, a candidate gene for human spinal muscular atrophy, leads to massive cell death in early mouse embryos. Proc Natl Acad Sci USA, $\underline{94}(18), 9920-9925$

Selenko P, Sprangers R, Stier G, Bühler D, Fischer U, Sattler, M (2001): SMN tudor domain structure and its interaction with the sm proteins. Nat Struct Biol, $\underline{8}(1), 27-31$

Shupliakov O, Bloom O, Gustafsson J S, Kjaerulff O, Low P, Tomilin, N, Pieribone V A, Greengard P, Brodin, L (2002): Impaired recycling of synaptic vesicles after acute perturbation of the presynaptic actin cytoskeleton. Proc Natl Acad Sci USA, 99 (22), 14476-14481

Tizzano E F, Cabot C, Baiget, M (1998): Cell-specific survival motor neuron gene expression during human development of the central nervous system: implications for the pathogenesis of spinal muscular atrophy. Am J Pathol, 153(2), 355-361

Torres-Benito L, Neher MF, Cano R, Ruiz R, Tabares L (2011): SMN Requirement for Synaptic Vesicle, Active Zone and Microtubule Postnatal Organization in Motor Nerve Terminals. PLoSOne 16(10):e26164

Trepel, M : Neuroanatomie Struktur und Funktion, 4 Auflage Elsevier, München 2003

Valko M, Leibfritz D, Moncol J, Cronin, M T D, Mazur M, Telser, J (2007): Free radicals and antioxidants in normal physiological functions and human disease. Int J Biochem Cell Biol, 39 (1), 44-84 
Vila L, Barrett E F, Barrett, J N (2003): Stimulation-induced mitochondrial [ca2+] elevations in mouse motor terminals: comparison of wild-type with SOD1-G93A. J Physiol (Lond), $\underline{549}$ (Pt 3), 719-728

Wang, J and Dreyfuss, G (2001): Characterization of functional domains of the SMN protein in vivo. J Biol Chem, 276(48), 45387-45393

Werth J L, Zhou B, Nutter L M, Thayer, S A (1994): 2',3'-Dideoxycytidine alters calcium buffering in cultured dorsal root ganglion. Molecular pharmacology, 45(6), 1119-24

Will, C L and Lührmann, R (2001): Spliceosomal UsnRNP biogenesis, structure and function. Current opinion in cell biology, 13(3), 290-301

Wimmer V C, Horstmann H, Groh A, Kuner, T (2006): Donut-like topology of synaptic vesicles with a central cluster of mitochondria wrapped into membrane protrusions: a novel structure-function module of the adult calyx of held. J Neurosci, 26 (1), 109-116

Winkler C, Eggert C, Gradl D, Meister G, Giegerich M, Wedlich D, Laggerbauer B, Fischer, U (2005): Reduced u snRNP assembly causes motor axon degeneration in an animal model for spinal muscular atrophy. Genes Dev, 19(19), 2320-2330

Wulf E, Deboben A, Bautz F A, Faulstich H, Wieland, T (1979): Fluorescent phallotoxin, a tool for the visualization of cellular actin. Proc Natl Acad Sci USA, 76(9), 4498-4502

Yuste R, Majewska A, Holthoff, K (2000): From form to function: calcium compartmentalization in dendritic spines. Nature neuroscience, $\underline{3}(7), 653-9$

Zhang H L, Pan F, Hong D, Shenoy S M, Singer R H, Bassell, G J (2003): Active transport of the survival motor neuron protein and the role of exon-7 in cytoplasmic localization. J Neurosci, 23(16), 6627-6637

Zhang, W and Benson, D L (2001): Stages of synapse development defined by dependence on f-actin. J Neurosci, 21(14), 5169-5181 


\title{
List of abbreviations
}

\author{
$\alpha$-BTX $\quad \alpha$-Bungarotoxin \\ ALS amyotrophic lateral sclerosis \\ cAMP cyclic adenosinmonophosphate \\ DeSyn delayed synapsing \\ EM electron microscopy \\ EPCs evoked endplate currents \\ FaSyn fast synapsing \\ $\mathrm{KO} \quad$ knockout \\ LAL levator auris longus \\ MEPC spontaneous miniature EPC \\ nAChR nicotinic acetylcholine receptor \\ NMJ neuro muscular junction \\ P7 postnatal day seven \\ P14 postnatal day fourteen \\ PCR polymerase chain reaction \\ RGG arginine glycine \\ ROS reactive oxygen species \\ $\mathrm{RRP}$ readily releasable pool \\ SMA spinal muscular atrophy \\ SMN survival motor neuron 1 \\ SV synaptic vesicles \\ SV2 synaptic vesicular transmembrane \\ Vdac2 voltage-dependent anion-selective protein 2 \\ WT wild-type
}




\section{Acknowledgements}

I would like to express my very great appreciation to my supervisor Prof. Dr. Lucia Tabares from the University of Sevilla, Spain, for giving me the opportunity to make my first scientific steps in a fascinating field, such as the pathology of Spinal Muscular Atrophy (SMA), for her scientific guidance and constant supervision during all my work, and above all for being a dedicated and admirable person, who is leading an expert and joyful lab. I would like to convey my special thanks to Laura Torres-Bonito, Raquel Cano, and Rocio Ruiz for teaching me all laboratory techniques and for being such great teammates.

I am particularly grateful for the valuable support and the help of my second supervisor Prof. Dr. Jochen Weishaupt in submitting my work at the University of Goettingen. Also, I would like to thank the Medical School of the University of Goettingen to encourage me to combine my study with international experience.

I would like to thank the Department of Medical Physiology and Biophysics at the School of Medicine in Sevilla and everyone, who contributed to turn my stay in Sevila into a time, in which I learned the wonderful Spanish language and culture, met inspiring people and had a great scientific experience through my studies about a motor neuron disease, such as SMA. 


\section{Curriculum Vitae}

I, Margret Neher, was born on the 18th of April 1987 in Göttingen and grew up as the fifth child of Eva-Maria Neher and Erwin Neher in Eddigehausen, a village near Göttingen. From 1994 to 2006 I visited the Rudolf Steiner School in Weende (Göttingen). During High School I went on a student exchange from October 2003 until April 2004 in Napier, New Zealand.

In April 2007 I started my medical studies at University of Göttingen and took my first state exam successfully in 2009. I completed my medical clerkships in Neurology (Tübingen, Germany), Psychiatrics (Göttingen, Germany), Cardiology (Oxford, Great Britain) and Dermatology (Rabat, Morocco). I obtained teaching experiences as an assistant at anatomy preparations in 2008 and physiology tutor to third semester students in 2009.

From 2000 to present I have been an active canoeist. My best achievements in Canoe Polo have been the gold medalist in the European Champion ships in 2003 and 2007, silver medalist in the World Champion ships 2004, 2008 and 2010 and again gold medalist of the World Games 2005. In flat water kayak racing, an olympic sport, I won 2006 the European Champion Under 23 Championship in K2 over 500m, and the German Championship senior in K1 over $200 \mathrm{~m}$ and $500 \mathrm{~m}$. With these achievements, I qualified among the top 10 preselection candidates for the 2008 Olympics in Peking.

From February to October 2010 I lived in Sevilla, Spain to perform all my experiments for my doctoral thesis in the lab of Prof. Lucia Taberes. The results are published in the journal PlosOne as indicated below.

After the clinical semesters I spent my practical year partly abroad. For the obligatory subjects Surgery and Internal Medicine I went to the Waid Spital in Zürich (Switzerland) from August to October 2012, to the Hospital Italiano, Buenos Aires (Argentina) from October 2012 to February 2013, and from February to April 2013 to Neu-Mariahilf in Goettingen. The optional subject, Neurology, I fulfilled at the Klinikum of the University of Goettingen. In spring 2014 I will prospectively conclude my medical studies.

\section{Publications:}

Torres-Benito L, Neher MF, Cano R, Ruiz R, Tabares L (2011)

SMN Requirement for Synaptic Vesicle, Active Zone and Microtubule Postnatal Organization in Motor Nerve Terminals

PLoSOne 6(10):e26164.doi:10.1371/journal.pone.002616 